\title{
Development of a Mesoscale Finite Element Constitutive Model for Fiber Kinking
}

\author{
Andrew C. Bergan ${ }^{1}$ \\ NASA Langley Research Center, Hampton, VA 23681 \\ Miguel Herráez ${ }^{2}$, Carlos González ${ }^{3}$, and Claudio S. Lopes ${ }^{4}$ \\ IMDEA Materials, Madrid, Spain
}

\begin{abstract}
A mesoscale finite element material model is proposed to analyze structures that fail by the fiber kinking damage mode. To evaluate the assumptions of the mesoscale model, the results were compared with those of a high-fidelity micromechanical model. A direct comparison between the two models shows remarkable correlation, indicating that the key features of the fiber kinking phenomenon are appropriately accounted for in the mesoscale model. The mesoscale model is applied to structural analysis cases to demonstrate the capabilities of the model. A verification study is conducted with an unnotched compression specimen and preliminary validation is demonstrated with a notched compression specimen. The results show that the model is successful at representing the kinematics of fiber kinking while at the same time highlighting the need for further verification and validation.
\end{abstract}

\section{Introduction}

$\mathrm{T}$ HERE is a need for more accurate progressive damage analysis (PDA) codes for predicting failure in fiber reinforced polymer (FRP) laminates, especially when loaded in compression. ${ }^{1}$ One factor limiting the accuracy of predictions by many state-of-the-art mesoscale PDA codes when fiber kinking is active is that most of the physical characteristics of the fiber kinking process are ignored. The conventional continuum damage mechanics (CDM) approach uses the same phenomenological model in longitudinal compression as it does in longitudinal tension despite differences in the failure process. ${ }^{2,3}$ The constitutive law is typically bilinear or trilinear with a fully damaged material point reaching a traction free state. Such models are not reasonable for compression failure modes in FRP laminates since compressive failure does not result in traction-free conditions. Instead, it is intuitive that, as long as the material remains in contact with itself, some residual stress state will exist through the failure process.

In typical CDM models, the stress-strain response is regularized using a fracture toughness. Although some authors have reported values for the longitudinal compressive fracture toughness determined experimentally, ${ }^{4-8}$ the range of values covers a factor of nearly two for nominally identical materials. Furthermore, in conventional CDM models, rotations associated with the fiber kinking process are ignored.

Recently, developers of mesoscale PDA methods have recognized the deficiencies of the conventional CDM approach for representing fiber compression failure and have proposed alternative approaches. Iarve et al. ${ }^{9}$ prevented a traction-free state by adding a constraint based on change in volume. Joseph et al. ${ }^{10}$ used a residual stress approach where the stress was set to a crush stress level after the failure criterion for fiber compression was met. Although practical, both approaches are unsatisfying because they lack a physically-based representation of the fiber kinking process.

The fiber kinking theory introduced by Budiansky offers a physically-based model for kink band initiation and propagation. ${ }^{11-13}$ Fiber kinking theory identifies the relevant mechanisms in kink band formation as a combination of an infinitely-wide band of initially misaligned fibers, nonlinear shear stress-strain behavior, and large fiber rotation. Fiber kinking theory produces the characteristic constitutive law shown in Fig. 1a where, once the strength, $X_{C}$, is reached, the stress drops unstably to a residual "crush stress" level. The kink band is idealized, as shown in Fig. 1b,

\footnotetext{
${ }^{1}$ Research Engineer, Structural Mechanics and Concepts Branch, MS 190, AIAA Member.

${ }^{2}$ Research Assistant, IMDEA Materials, c/Eric Kandel 2, 28906 Getafe, Madrid, Spain.

${ }^{3}$ Senior Researcher, IMDEA Materials, c/Eric Kandel 2, 28906 Getafe, Madrid, Spain.

${ }^{4}$ Senior Researcher, IMDEA Materials, c/Eric Kandel 2, 28906 Getafe, Madrid, Spain.
}

American Institute of Aeronautics and Astronautics 
with a fiber misalignment angle, $\varphi$, kink band angle, $\beta$, and kink band width, $w_{\mathrm{kb}}$. If the shear nonlinearity follows a Ramberg-Osgood ${ }^{14}$ behavior, $\gamma_{12}=\left(\tau+\alpha \tau_{12}^{\eta}\right) / G_{12}$, fiber kinking theory predicts the strength as

$$
X_{C}=\frac{G_{12}}{1+\eta \alpha^{1 / \eta}\left(\frac{G_{12} \varphi_{0}}{\eta-1}\right)^{\frac{\eta-1}{\eta}}}
$$

where $G_{12}$ is the in-plane shear modulus, $\alpha$ and $\eta$ define the shape of the shear stress-strain curve, and $\varphi_{0}$ is an initial fiber misalignment.

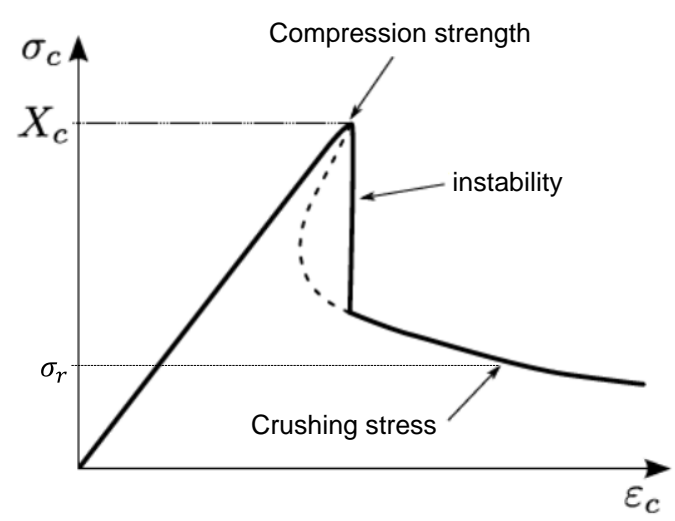

a)

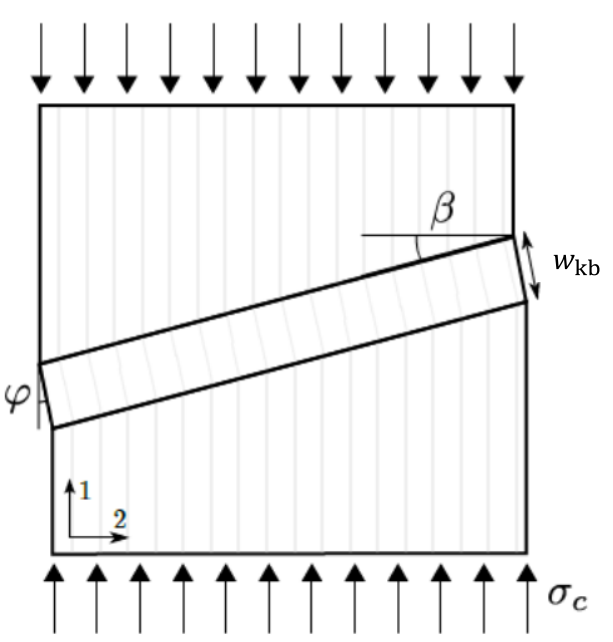

b)

Figure 1. The (a) characteristic constitutive response predicted by fiber kinking theory and (b) idealization of the kink band.

Budiansky ${ }^{13}$ also addressed the crushing (residual) stress, $\sigma_{r}$, by considering the behavior at large fiber rotations to derive the expression

$$
\sigma_{r}=\frac{2 \tau_{L}}{\sin 2 \beta}
$$

where $\tau_{L}$ is the shear stress associated with large rotations. While $\tau_{L}$ is somewhat arbitrary and no expression is given to determine $\beta$, by selecting $\tau_{L}$ and $\beta$ based on experimental data, Eqn. (2) provides an approximate value for the nonzero residual stress after a kink band has developed.

Recently, two similar constitutive models for fiber compression have been proposed that are a significant departure from the conventional CDM approach. Bergan and Leone proposed a model based on fiber kinking theory that uses the deformation gradient decomposition method to account for the coupling between longitudinal splitting and fiber kinking. ${ }^{15}$ The model predictions show that large rotations and shear nonlinearity dominate the response. Likewise, Gutkin, Costa, and Olsson recently introduced a constitutive model based on fiber kinking theory and a physically based constitutive law. ${ }^{16-18}$ The model includes consideration for fiber misalignments and nonlinear shear stress-strain behavior. The authors demonstrated that the model is capable of predicting the compression strength and crush stress. However, neither of these models have been thoroughly validated so far.

Validation of models for fiber kinking is a challenging undertaking due to the instability of the fiber kinking process. Most experimental configurations exhibit unstable failure or interaction of kinking with other damage mechanisms yielding limited data for model validation. In the absence of detailed experimental investigations of fiber kinking, computational micromechanics has much utility in providing an alternative basis for evaluating the assumptions of models derived at the mesoscale. Recently, high-fidelity three-dimensional (3-D) computational micromechanical models of fiber kinking have been introduced ${ }^{19-23}$ and have shown promise as a source of insight into the fiber kinking process.

In this paper, the mesoscale fiber kinking model proposed by Bergan and Leone ${ }^{15}$ is further developed with the end goal of generating an accurate simulation of a compressive failure in a notched specimen. The constitutive formulation and implementation details are discussed in Section II. In the following section, the computational

American Institute of Aeronautics and Astronautics 
micromechanical model proposed by Naya et al. ${ }^{23}$ is adapted for use in evaluating the assumptions of the mesoscale model. Section IV describes a direct comparison between the mesoscale and micromechanical models, highlighting the efficacy of the mesoscale model. Finally, in Section V, the mesoscale model is applied in two cases: verification with an unnotched compression specimen, and validation with a notched compression specimen.

\section{Mesoscale Constitutive Model}

A mesoscale constitutive model based on Budiansky's fiber kinking theory ${ }^{11-13}$ with $\beta=0$ is formulated in this section with the aim of representing the fiber kinking phenomenon using geometric nonlinearity and shear nonlinearity. The model includes the kinematics of the fiber kinking process by tracking fiber misalignment throughout loading. The characteristic constitutive response shown in Fig. 1a is not directly prescribed in the model. Instead, the response is a result of the shear nonlinearity and large rotation of the fiber direction. The model is formulated in the context of continuum damage mechanics and integrated into the existing code CompDam, ${ }^{24}$ which is a NASA user-subroutine for predicting damage in carbon fiber reinforced polymer laminates. The deformation gradient decomposition (DGD) method ${ }^{25}$ is used for accurate representation of the kinematics of the kink band and fiber misalignments.

\section{A. Constitutive Model Formulation}

The material model computes the stress state given the current deformation, state variables, and material properties as follows. Consider a material point with a reference frame, $\boldsymbol{X}_{i}$. An initial fiber misalignment angle, $\varphi_{0}$, is assumed such that a fiber-aligned reference frame, $\boldsymbol{X}_{i}^{\prime}$, is defined with rotation, $\boldsymbol{R}$, as

$$
\boldsymbol{R}=\left[\begin{array}{ccc}
\cos \varphi_{0} & -\sin \varphi_{0} & 0 \\
\sin \varphi_{0} & \cos \varphi_{0} & 0 \\
0 & 0 & 1
\end{array}\right]
$$

For a given deformation, $\boldsymbol{F}$, the Green-Lagrange strain, $\boldsymbol{E}$, is calculated as

$$
\boldsymbol{E}=\frac{1}{2}\left(\boldsymbol{F}^{T} \boldsymbol{F}-\boldsymbol{I}\right)
$$

Shear nonlinearity is accounted for in the $\boldsymbol{X}_{1}^{\prime}-\boldsymbol{X}_{2}^{\prime}$ plane using a one-dimensional (1-D) plasticity model based on the Ramberg-Osgood stress-strain law as follows

$$
\boldsymbol{E}^{\prime}=\boldsymbol{R}^{\boldsymbol{T}} \boldsymbol{E} \boldsymbol{R}-\frac{\gamma_{12}^{P L}}{2}\left[\begin{array}{lll}
0 & 1 & 0 \\
1 & 0 & 0 \\
0 & 0 & 0
\end{array}\right]
$$

where the plastic portion of the shear strain, $\gamma_{12}^{P L}=\gamma_{12}-\gamma_{12}^{E L}$, is found iteratively using

$$
\gamma_{12}=\frac{1}{G_{12}}\left[\tau_{12}+\operatorname{sign}\left(\tau_{12}\right) \alpha\left|\tau_{12}\right|^{\eta}\right]
$$

where $\tau_{12}$ is the shear stress and $G_{12}, \alpha$, and $\eta$ are the material properties that define the Ramberg-Osgood curve. The second Piola-Kirchoff stress in the fiber-aligned reference frame, $\boldsymbol{S}^{\prime}$, is calculated using the elastic stiffness tensor, $\mathbf{C}$

$$
\boldsymbol{S}^{\prime}=\mathbf{C}: \boldsymbol{E}^{\prime}
$$

with

$$
\mathbf{C}=\mathbf{H}^{-\mathbf{1}}
$$




$$
\mathbf{H}=\left[\begin{array}{cccccc}
\frac{1}{E_{1}^{*}} & \frac{-v_{21}}{E_{2}} & \frac{-v_{31}}{E_{3}} & 0 & 0 & 0 \\
\frac{-v_{12}}{E_{1}^{*}} & \frac{1}{E_{2}} & \frac{-v_{32}}{E_{3}} & 0 & 0 & 0 \\
\frac{-v_{13}}{E_{1}^{*}} & \frac{-v_{23}}{E_{2}} & \frac{1}{E_{3}} & 0 & 0 & 0 \\
0 & 0 & 0 & \frac{1}{G_{12}} & 0 & 0 \\
0 & 0 & 0 & 0 & \frac{1}{G_{23}} & 0 \\
0 & 0 & 0 & 0 & 0 & \frac{1}{G_{13}}
\end{array}\right]
$$

using the typical elastic constants. Fiber nonlinearity is accounted for following Le Goff et al. ${ }^{26}$ as

$$
E_{1}^{*}=E_{1}\left(1+c_{l} \varepsilon_{11}\right)
$$

where $c_{l}$ is the nonlinearity coefficient for the ply and is an additional material property to be obtained from test data. In the reference frame, $\boldsymbol{X}_{i}$, the second Piola-Kirchoff stress is

$$
S=R S^{\prime} R^{T}
$$

Finally, the Cauchy stress is calculated.

$$
\sigma=F S F^{T}|F|^{-1}
$$

This model has been implemented in Abaqus/Explicit ${ }^{27}$ as a VUMAT. The following sub-sections include practical considerations for implementation as a finite element user-subroutine.

\section{B. Initial Misalignment Angle}

The initial misalignment angle, $\varphi_{0}$, accounts for fiber misalignments and other manufacturing anomalies that may contribute to fiber kinking initiation. The initial fiber misalignment is calculated by rearranging Eq. (1) as

$$
\varphi_{0}=\frac{\eta-1}{G_{12}}\left(\frac{G_{12}-X_{C}}{X_{C} \eta \alpha^{1 / \eta}}\right)^{\frac{\eta}{\eta-1}}
$$

such that $\varphi_{0}$ is fully defined in terms of material property inputs. Some authors have suggested that $X_{C}$ is not a material property due to the variation in measured values for $X_{C}$ with specimen size and test configuration. ${ }^{28,29}$ The dependence of the present model on $X_{C}$ as a material property input could be eliminated by considering experimentally measured fiber misalignments. A first step towards using experimentally measured fiber misalignments is investigated by considering the spatial variation of $\varphi_{0}$ in Section V.

\section{Decomposition}

Material models that exhibit strain-softening behavior are susceptible to mesh sensitivity when strain localizes. In conventional CDM models, this deficiency is often addressed with Bažant's crack band theory ${ }^{30}$ in which the dissipated energy is scaled by the element size. In the present model, there is no crack surface on which traction goes to zero and therefore the crack band theory is not applicable. Nonetheless, there is an inherent mesh sensitivity since the model includes a strain-softening response leading to strain localization in a band of elements after the strength is reached. Recently, Costa et al. identified this mesh sensitivity as it relates to modeling fiber kinking and recommended two options for ensuring mesh objectivity. ${ }^{17}$ In the first method, the strain in the element is decomposed into a kinkband component and an elastic component. In the second method, the strain in the kink band is smeared over the element. The method used herein is analogous to the strain decomposition method by Costa et al. ${ }^{17}$ and follows previous work by Bergan and Leone. ${ }^{15}$

When the plastic strain becomes non-negligible the decomposition is performed. In the decomposed element, shear nonlinearity is enabled in the kink band region, whereas in the undamaged material region the shear response is linear. 
The kink band width, $w_{\mathrm{kb}}$, is assumed to be smaller than the element size in the 1-direction, $l_{1}$. When $w_{\mathrm{kb}} / l_{1} \leq 0.95$, the element is decomposed into an undamaged region and a kink band region, as shown in Fig. 2, in order to preserve mesh objectivity. When $w_{\mathrm{kb}} / l_{1}>0.95$, the kink band width is close to the element size, so the material model described in the previous sections is applied directly without decomposition of the element. When the element is decomposed, the DGD approach ${ }^{15,25}$ is used to enforce continuity and equilibrium between the undamaged and kink band regions as follows.

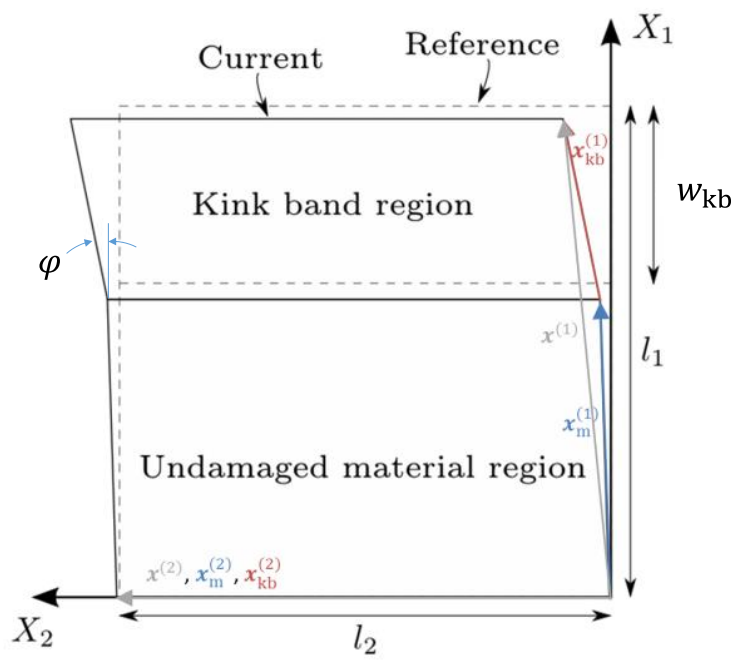

Figure 2. Schematic representation of the model: decomposition into the kink band and undamaged regions.

Consider a rectangular continuum of fiber-reinforced material where the fiber direction is initially aligned with the reference $X_{1}$-direction. The reference configuration is defined as

$$
\boldsymbol{X}=\left[\begin{array}{ccc}
l_{1} & 0 & 0 \\
0 & l_{2} & 0 \\
0 & 0 & l_{3}
\end{array}\right]
$$

where the nonzero diagonal components are the undeformed dimensions of the continuum. The current configuration, $\boldsymbol{x}$, is a function of $\boldsymbol{X}$ and the deformation gradient, $\boldsymbol{F}$

$$
\boldsymbol{x}=\boldsymbol{F} \boldsymbol{X}
$$

$\boldsymbol{F}$ is decomposed into a deformation gradient for the undamaged material, $\boldsymbol{F}_{m}$, and a deformation gradient for the kink band, $\boldsymbol{F}_{\mathrm{kb}}$. In the fiber direction, compatibility of the deformations requires

$$
\boldsymbol{x}^{(1)}=\left(1-\omega_{\mathrm{kb}}\right) x_{m}^{(1)}+\omega_{\mathrm{kb}} x_{\mathrm{kb}}^{(1)}
$$

where the superscript ${ }^{(1)}$ indicates the first column of $\boldsymbol{x}$ and $\omega_{\mathrm{kb}}=w_{\mathrm{kb}} / l_{1}$. Substituting Eqs. (14) and (15) into Eq. (16)

$$
\boldsymbol{F} \boldsymbol{X}^{(1)}=\left(1-\omega_{\mathrm{kb}}\right) \boldsymbol{F}_{m} \boldsymbol{X}^{(1)}+\omega_{\mathrm{kb}} \boldsymbol{F}_{\mathrm{kb}} \boldsymbol{X}^{(1)}
$$

then simplifying and rearranging yields an expression for $\boldsymbol{F}_{\mathrm{kb}}$ in the 1-direction

$$
\boldsymbol{F}_{\mathrm{kb}}^{(1)}=\frac{1}{\omega_{\mathrm{kb}}} \boldsymbol{F}^{(1)}+\left(1-\frac{1}{\omega_{\mathrm{kb}}}\right) \boldsymbol{F}_{m}^{(1)}
$$

In the 2-direction, there is no decomposition, so compatibility of the deformation requires

$$
x_{\mathrm{kb}}^{(2)}=x_{m}^{(2)}=x^{(2)}
$$

Substituting Eq. (15) into Eq. (19) and simplifying yields

$$
\boldsymbol{F}_{\mathrm{kb}}^{(2)}=\boldsymbol{F}_{m}^{(2)}=\boldsymbol{F}^{(2)}
$$

American Institute of Aeronautics and Astronautics 
Using Eqs. (18) and (20) with $\boldsymbol{F}$ provided as an input, the quantities $\boldsymbol{F}_{m}$ and $\boldsymbol{F}_{\mathrm{kb}}$ can be determined in terms of the unknown $\boldsymbol{F}_{m}^{(1)}$ using equilibrium as described in the following section.

\section{Equilibrium and Solution Procedure}

It is necessary to ensure that the tractions that arise in the kink-band region and in the neighboring undamaged material region are in equilibrium. Equilibrium in the current fiber direction, $\hat{\boldsymbol{e}}_{f}$, is enforced between the kind-band region and the neighboring undamaged material region, where the current misaligned reference frame in the kink band is

$$
\boldsymbol{R}=\left[\begin{array}{lll}
\hat{\boldsymbol{e}}_{f} & \hat{\boldsymbol{e}}_{n} & \hat{\boldsymbol{e}}_{t}
\end{array}\right]
$$

where the unit vectors are defined as

$$
\begin{gathered}
\boldsymbol{e}_{f}=\boldsymbol{F}_{\mathrm{kb}}\left[\begin{array}{c}
\cos \varphi_{0} \\
\sin \varphi_{0} \\
0
\end{array}\right] \\
\boldsymbol{e}_{n}=\boldsymbol{F}_{\mathrm{kb}}^{-T}\left[\begin{array}{c}
-\sin \varphi_{0} \\
\cos \varphi_{0} \\
0
\end{array}\right] \\
\boldsymbol{e}_{t}=\boldsymbol{e}_{f} \times \boldsymbol{e}_{n}
\end{gathered}
$$

The current fiber misalignment is obtained from Eqns. (21) - (24) as

$$
\varphi=\tan ^{-1}\left(\frac{R_{21}}{R_{11}}\right)
$$

Cauchy's stress theorem is used to obtain the stress vector acting on a plane defined by the fiber direction in the kink band

$$
\boldsymbol{t}_{\mathrm{kb}}=\boldsymbol{\sigma}_{\mathrm{kb}} \cdot \hat{\boldsymbol{e}}_{f}
$$

where $\boldsymbol{\sigma}_{\mathrm{kb}}$ is calculated from Eqs. (4) to (12). Likewise, in the undamaged material

$$
\boldsymbol{t}_{m}=\boldsymbol{\sigma}_{m} \cdot \hat{\boldsymbol{e}}_{f}
$$

where $\boldsymbol{\sigma}_{m}$ is also calculated from Eqs. (4) to (12) with the exception that the second term in (5) is omitted. An iterative solution procedure is required to solve for the state of stress at equilibrium. A residual stress vector, $\boldsymbol{t}_{\mathrm{res}}$, is defined in terms of the stress vectors in Eqs. (26) and (27) in the current misaligned coordinate system as

$$
\boldsymbol{t}_{\mathrm{res}}=\boldsymbol{R}^{T}\left(\boldsymbol{t}_{m}-\boldsymbol{t}_{\mathrm{kb}}\right)
$$

Newton-Raphson iteration is used to solve Eq. (28) for $\boldsymbol{F}_{m}^{(1)}$. The iterations are determined to be converged when $\boldsymbol{t}_{\text {res }}$ is less than a tolerance. Herein, $0.01 \%$ of the shear strength was used as the tolerance.

\section{E. Kink Band Width}

While the model includes fiber rotation, bending in the fibers is ignored. As a result of this assumption, $w_{\mathrm{kb}}$ cannot be predicted by the model and so $w_{\mathrm{kb}}$ is a required input. Average values of $w_{\mathrm{kb}}$ reported in the literature are summarized in Table 1. Budiansky ${ }^{11}$ derived an expression for $w_{\mathrm{kb}}$ by accounting for inextensional bending of the fibers and suggested a kink band width of about 12 fiber diameters. Herein, $w_{\mathrm{kb}}=0.1 \mathrm{~mm}$ was used, which is on the order of reported values for AS4/8552. 
Table 1. Values of $w_{\mathrm{kb}}$ reported in the literature.

\begin{tabular}{|c|c|c|c|}
\hline Reference & $w_{\mathrm{kb}}[\mu \mathrm{m}]$ & Method & $\begin{array}{l}\text { Material } \\
\text { System }\end{array}$ \\
\hline Svensson et al. ${ }^{31}$ & 200 & Microscopy & HTS/RTM6 \\
\hline Zobeiry et al. ${ }^{32}$ & 50 & Microscopy & IM7/8552 \\
\hline Laffan et al. ${ }^{6}$ & 25 & Microscopy & IM7/8552 \\
\hline Hapke et al. ${ }^{33}$ & 55 & Microscopy & T700/977-2 \\
\hline Jumahat et al. ${ }^{34}$ & 80 & Microscopy & HTS40/977-2 \\
\hline Gutkin et al..$^{35}$ & 50 & Microscopy & $\mathrm{T} 800 / 924$ \\
\hline Pinho et al. ${ }^{4}$ & 70 & Microscopy & T300/913 \\
\hline Soutis ${ }^{36}$ & 55 & Microscopy & $\mathrm{T} 800 / 924 \mathrm{C}$ \\
\hline $\begin{array}{l}\text { Bergan and } \\
\text { Garcea }^{37}\end{array}$ & 25 & $\begin{array}{c}\text { In-Situ X-Ray Computed } \\
\text { Tomography }\end{array}$ & IM7/8552 \\
\hline Bai et al. ${ }^{22}$ & 49 & Micromechanical, FE & AS4/3501 \\
\hline Naya et al. ${ }^{23}$ & 120 & Micromechanical, FE & AS4/8552 \\
\hline
\end{tabular}

\section{F. Element Deletion}

Fiber kinking often occurs at or near collapse and may correspond with a substantial release of energy. As a result, difficulties including excessive mesh distortion, excessive deformation rate, or failure to find a converged solution to Eqn. (28) may occur in an analysis, especially for problems that fail by unstable collapse. When one of these errors occurs and the analysis terminates, the strength prediction is ambiguous because, while the analysis output indicates the type of error that occurs, no load drop is predicted. Consequently, it is unclear when structural failure occurs. To circumvent these runtime errors, element deletion can be enabled by specifying values for the following conditions

$$
\begin{gathered}
\left|\boldsymbol{F}_{\mathrm{kb}}\right| \leq F_{\mathrm{TOL}} \\
n_{\mathrm{NR}}>n_{\max } \\
\left|\gamma_{12}\right|>\gamma_{\mathrm{TOL}}
\end{gathered}
$$

where $\left|\boldsymbol{F}_{\mathrm{kb}}\right|$ is the determinant of $\boldsymbol{F}_{\mathrm{kb}}, n_{\mathrm{NR}}$ is the number of Newton-Raphson iterations, and $\left|\gamma_{12}\right|$ is the absolute value of $\gamma_{12}$. When any of the conditions in Eqns. (29)-(31) is satisfied, the element is deleted. Element deletion is disabled in the analyses discussed in the subsequent sections unless where noted.

\section{G. Implementation}

The model described in the previous sections is implemented into the CompDam VUMAT for Abaqus and is available as an open source software. ${ }^{24}$ The present model augments the existing capabilities of CompDam for representation of matrix damage using the DGD method. ${ }^{25}$ The capability to include spatial variation of the initial fiber misalignment angle is included in the subroutine. The studies described in sections IV and V document the initial effort toward verification and validation of the CompDam code for longitudinal compression failure.

\section{Computational Micromechanics Model}

A 3-D single-fiber computational micromechanical (CMM) model is used to interrogate the assumptions of the relatively coarse mesoscale model. The micromechanical finite element model is an extension of the single fiber model described in Naya et al, ${ }^{23}$ where it was demonstrated that a single fiber representative volume element (RVE) produces strength predictions in good agreement with a multi-fiber RVE. The 3-D single fiber model is used here since it is a good compromise between computational expense and accuracy. A trade-study between dozens of different models demonstrated that single-fiber and multi-fiber two-dimensional (2-D) models were less accurate than 3-D single fiber models. Multi-fiber 3-D models were not used due to convergence difficulties and computational expense.

In this section, the micromechanical finite element model is described including the geometry, discretization, and material properties. Subsequently, a calibration study that was conducted to demonstrate equivalence between the shear behavior of the mesoscale and micromechanical models is described.

American Institute of Aeronautics and Astronautics 


\section{A. 3-D RVE for Fiber Kinking}

The RVE model, shown in Fig. 3, represents a single carbon fiber extruded in the longitudinal direction $z$, along the half wavelength of a sine curve. An initial misalignment is imposed according to

$$
y(z)=L \frac{\varphi_{0}}{\pi}\left(1-\cos \left(\pi \frac{z}{L}\right)\right)
$$

such that the initial misalignment varies along the length, $L$, of the fiber, with section definitions defined according to the local misalignment. The model length was set at $500 \mu \mathrm{m}$ and periodic boundary conditions are imposed following Gutkin et al. ${ }^{38}$

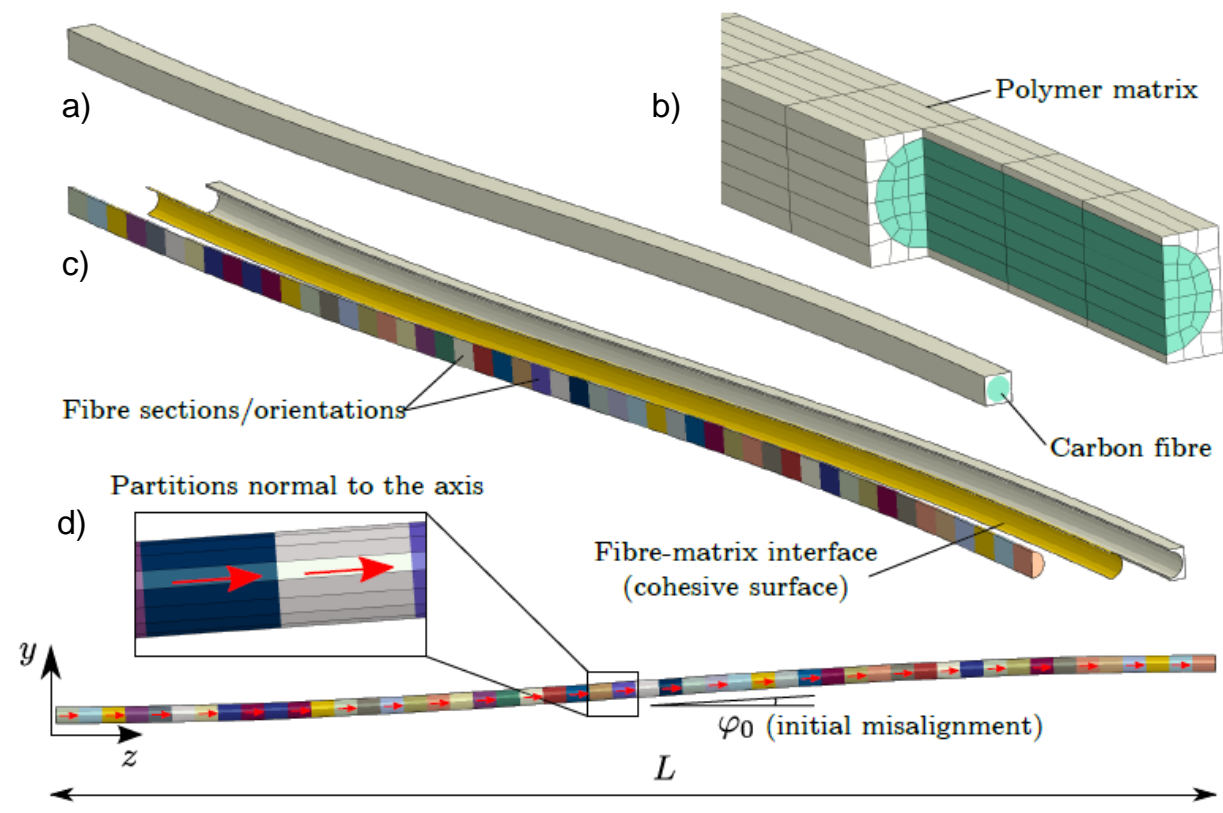

Figure 3. Illustration of the (a) single-fiber 3-D model, (b) detail of the mesh, (c) exploded cut view of the model, and (d) side view with detail of the longitudinal mesh and material orientation.

The carbon fibers are assumed to behave as an elastic transversely isotropic material with the elastic constants defined in Table 2 for the AS4/8552 material system. Fiber nonlinearity is accounted for by using the same expression, Eqn. (10), as used for the CDM model, with the fiber nonlinearity coefficient denoted as $c_{f}$. The fiber diameter is $7.09 \mu \mathrm{m}$ and a fiber volume fraction of $65 \%$ was assumed. The matrix behavior is represented using the Lubliner damage-plasticity model included in Abaqus/Standard. ${ }^{27}$ This constitutive equation allows the material to behave as quasi-brittle when subjected to dominant tensile stress and models elasto-plastic behavior under pressure confinement and compressive loads. Hence, the tensile response is linear and elastic, with modulus and Poisson ratio, $E_{m}$ and $v_{m}$, respectively, until the tensile failure stress, $\sigma_{t 0}$, is reached. Beyond this point, a quasi-brittle softening is induced in the material, with $G_{t}$ being the matrix fracture energy. Under uniaxial compression, the response is linear up to the initial yield limit, $\sigma_{c 0}$. Then, strain hardening takes place until the ultimate stress value, $\sigma_{\mathrm{cu}}$, is reached. Finally, the model includes a dilatancy parameter, $\Psi$, for the matrix. The matrix plasticity/damage model parameters used in the simulations are reported in Table 3 with the exception of $\Psi$, which is established in the following section since no experimental evidence for $\Psi$ was available. Fiber-matrix interface failure is taken into account by using a cohesive crack approach. To this end, a cohesive interaction between the fiber and the matrix surfaces was defined. The cohesive interaction is governed by a mixed-mode traction-separation law where damage onset is controlled by a quadratic stress criterion with normal strength, $N$, and shear strength, $S$. Damage evolution is governed by a mixed-mode Benzeggagh-Kenane ${ }^{39}$ fracture law. Isotropic Coulomb friction with coefficient of friction, $\xi$, is included in the interaction definition and is activated after cohesive failure. The interface parameters used in the simulations are provided in Table 4.

American Institute of Aeronautics and Astronautics 
Table 2. Material properties of AS4 carbon fibers. ${ }^{40}$

\begin{tabular}{|c|c|c|c|c|c|c|c|}
\hline $\begin{array}{c}E_{1 f} \\
(\mathrm{GPa})\end{array}$ & $\begin{array}{c}E_{2 f} \\
(\mathrm{GPa})\end{array}$ & $v_{12 f}$ & $v_{23 f}$ & $\begin{array}{c}G_{12 f} \\
(\mathrm{GPa})\end{array}$ & $\begin{array}{c}G_{23 f} \\
(\mathrm{GPa})\end{array}$ & $\begin{array}{c}\alpha_{1 f} \\
\left(10^{-6} \mathrm{~K}^{-1}\right)\end{array}$ & $\begin{array}{c}\alpha_{2 f} \\
\left(10^{-6} \mathrm{~K}^{-1}\right)\end{array}$ \\
\hline 231.6 & 12.97 & 0.3 & 0.46 & 11.3 & 4.45 & -0.9 & 7.2 \\
\hline
\end{tabular}

Table 3. Parameters for the matrix damage plasticity model. ${ }^{41}$

\begin{tabular}{|c|c|c|c|c|c|c|}
\hline $\begin{array}{c}E_{m} \\
(\mathrm{GPa})\end{array}$ & $v_{m}$ & $\begin{array}{c}\alpha_{m} \\
\left(10^{-6} \mathrm{~K}^{-1}\right)\end{array}$ & $\begin{array}{c}\sigma_{t 0} \\
(\mathrm{MPa})\end{array}$ & $\begin{array}{c}G_{t} \\
\left(\mathrm{~J} / \mathrm{m}^{2}\right)\end{array}$ & $\begin{array}{c}\sigma_{c 0} \\
(\mathrm{MPa})\end{array}$ & $\begin{array}{c}\sigma_{\mathrm{cu}} \\
(\mathrm{MPa})\end{array}$ \\
\hline 5.07 & 0.35 & 52.0 & 121 & 90 & 176 & 180 \\
\hline
\end{tabular}

Table 4. Properties of the fiber-matrix interface. ${ }^{42}$

\begin{tabular}{|c|c|c|c|c|c|}
\hline $\begin{array}{c}N \\
(\mathrm{MPa})\end{array}$ & $\begin{array}{c}S \\
(\mathrm{MPa})\end{array}$ & $\begin{array}{c}G_{N}^{c} \\
\left(\mathrm{~J} / \mathrm{m}^{2}\right)\end{array}$ & $\begin{array}{c}G_{S}^{c} \\
\left(\mathrm{~J} / \mathrm{m}^{2}\right)\end{array}$ & $\eta_{\text {BK }}$ & $\xi$ \\
\hline 57 & 85 & 7 & 81 & 1.2 & 0.4 \\
\hline
\end{tabular}

The model is discretized with 8-node solid elements in Abaqus/Standard. ${ }^{27}$ The matrix is meshed with fully integrated elements (C3D8) while the fiber is meshed with reduced integration elements (C3D8R). The in-plane element size is approximately $1 \mu \mathrm{m}$ square and the element edge length in the longitudinal direction is $10 \mu \mathrm{m}$. A thermal step with a temperature drop, $\Delta T$, was applied prior to the loading step to consider the residual thermal stresses induced by the cool down from the curing temperature. The magnitude $\Delta T$ is not easily determined since the residual stresses accumulate nonlinearly during the cool down. As a result, the value used for $\Delta T$ is determined as described in the next section.

\section{B. Calibration of In-Plane Shear Response}

The mesoscale model utilizes a Ramberg-Osgood shear nonlinearity curve. ${ }^{14}$ Ideally, the parameters that define the shear nonlinearity are obtained from a test that isolates the behavior of a single ply subjected to large shear deformations. However, in the absence of such test data, the ASTM D3518 test of a $\pm 45^{\circ}$ laminate subjected to tensile loads ${ }^{43}$ was used to define the nonlinear shear behavior. The $\pm 45^{\circ}$ laminate test data smears a wide variety of damage mechanisms into a single response, including mechanisms such as large fiber rotations and delaminations, which are not intended to be included in the shear nonlinearity characterization. Nonetheless, the $\pm 45^{\circ}$ laminate is the best source of material input data available for the mesoscale model. Therefore, the micromechanical model was calibrated, in a similar fashion to the approach used by Yerramalli and Waas, ${ }^{19}$ so that the model produces an equivalent shear stressstrain response using a representative RVE. This approach facilitates a one-to-one comparison of the mesoscale and micromechanical models for the fiber kinking.

The RVE of a $\pm 45^{\circ}$ laminate shown in Fig. 4 was developed with the parameters and modeling approach described in the previous section. The two undefined input parameters, the dilatancy angle of the matrix, $\Psi$, and the temperature drop, $\Delta T$, were adjusted by trial-and-error to reproduce the experimentally measured stress-strain response. ${ }^{44}$ The final response produced from the $\pm 45^{\circ}$ micromechanical RVE, the experimentally measured response of $\mathrm{a} \pm 45^{\circ}$ laminate, and the Ramberg-Osgood curve fit are nearly identical, as shown in Fig. 5.

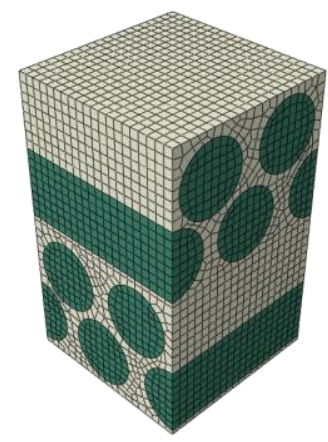

a)

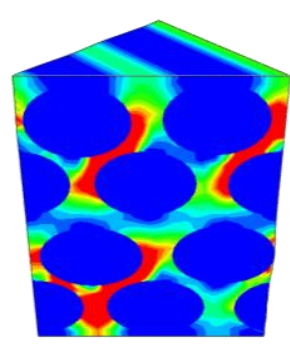

b)

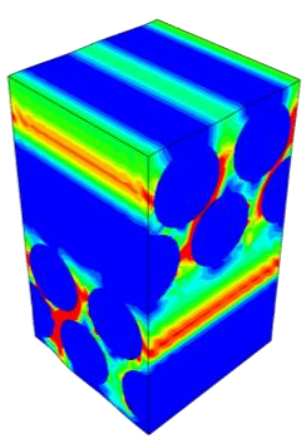

Figure 4. Micromechanical $\pm 45^{\circ} \mathrm{RVE}$ mesh (a) and representative plastic strain field in the matrix (b).

American Institute of Aeronautics and Astronautics 


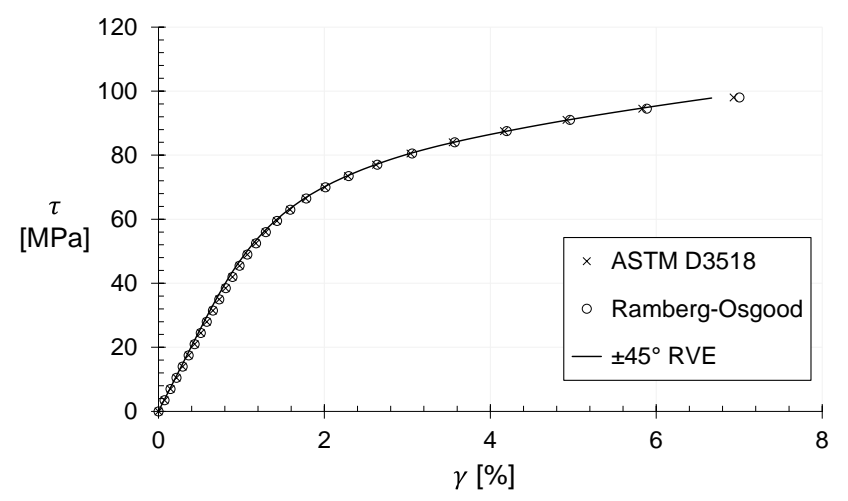

Figure 5. Comparison of the shear stress-strain curves from experimental tests following ASTM D3518, the corresponding Ramberg-Osgood fit, and the $\pm 45^{\circ} \mathrm{RVE}$ calibrated to match the test data.

\section{Comparison of the Mesoscale CDM and Micromechanical Models}

The predictions from the micromechanical model were compared with the predictions from the mesoscale model to understand the role of simplifying assumptions in the mesoscale model. In both analyses, an end-shortening displacement in the longitudinal direction was prescribed. The mesoscale finite element model is composed of one cubic C3D8R element with an edge length, $l_{e}=0.15 \mathrm{~mm}$. The material properties used in the mesoscale analysis are provided in Table 5 . The fiber nonlinearity parameters $c_{l}$ and $c_{f}$ are set to zero, except where noted.

Table 5. AS4/8552 material properties inputs for mesoscale model ${ }^{44}$.

\begin{tabular}{|c|c|c|c|c|c|c|c|}
\hline $\begin{array}{c}E_{1} \\
(\mathrm{MPa})\end{array}$ & $\begin{array}{c}E_{2} \\
(\mathrm{MPa})\end{array}$ & $\begin{array}{c}G_{12} \\
(\mathrm{MPa})\end{array}$ & $v_{12}$ & $v_{23}$ & $\begin{array}{c}\alpha \\
\left(\mathrm{MPa}^{1-\eta_{\mathrm{PL}}}\right)\end{array}$ & $\eta$ & $\begin{array}{c}X_{C} \\
(\mathrm{MPa})\end{array}$ \\
\hline 131,600 & 9239 & 4830 & 0.3 & 0.45 & $2.86 \times 10^{-11}$ & 6.49 & 1480 \\
\hline
\end{tabular}

The predicted stress-strain curves indicate excellent agreement between the two models for a variety of initial fiber misalignments, $\varphi_{0}$ of $1.5^{\circ}, 2^{\circ}, 3^{\circ}$, and $4^{\circ}$, as shown in Fig. 6 . The compressive stress $\sigma_{c}$ is the nominal stress calculated as the reaction force divided by the original area, and the compressive strain $\varepsilon_{c}$ is the end shortening divided by the original length. Both models predict the initial elastic response, strength, subsequent collapse, and finally a nonzero residual stress. Since the energy released during the instability is large for small values of $\varphi_{0}$, some vibrations are predicted by both models immediately after the instability. Rayleigh damping was added to the mesoscale model to limit the vibrations. The damping coefficient $\alpha_{R}$ was set to $10^{4}$ such that the vibrations were limited but the overall results remained similar to the undamped case. The transition from a strong instability (snap-back) to a smooth response occurs between $\varphi_{0}=2^{\circ}$ and $3^{\circ}$. The results shown in Fig. 6 illustrate that both models predict a dependence of the peak load on $\varphi_{0}$ whereas the predicted residual stress, $\sigma_{r}$, is independent of $\varphi_{0}$, which is consistent with fiber kinking theory. A range of $\sigma_{r}$ calculated using Eqn. (2) is superimposed on the figure showing very good agreement with the model predictions, where the shear strength at $5 \%$ strain $\tau_{L}=95 \mathrm{MPa}$ and $\beta=12^{\circ}$ to $16^{\circ}$, as reported from an experimental investigation, were used in Eqn. (2). The excellent agreement between the two models for strength, subsequent instability, and crush stress suggests that the most significant features of the kinking process are captured by the relatively simple mesoscale model. Further, the agreement between the two models demonstrates that ignoring fiber bending is a reasonable assumption for prediction of fiber kinking strength and crush stress. This assumption may not hold for large fibers (e.g. glass) or misalignments with short wavelengths as noted in the literature ${ }^{19,28}$. Nonetheless, ignoring fiber bending appears to be a reasonable assumption for relatively small carbon fibers with large wavelength misalignments.

American Institute of Aeronautics and Astronautics 


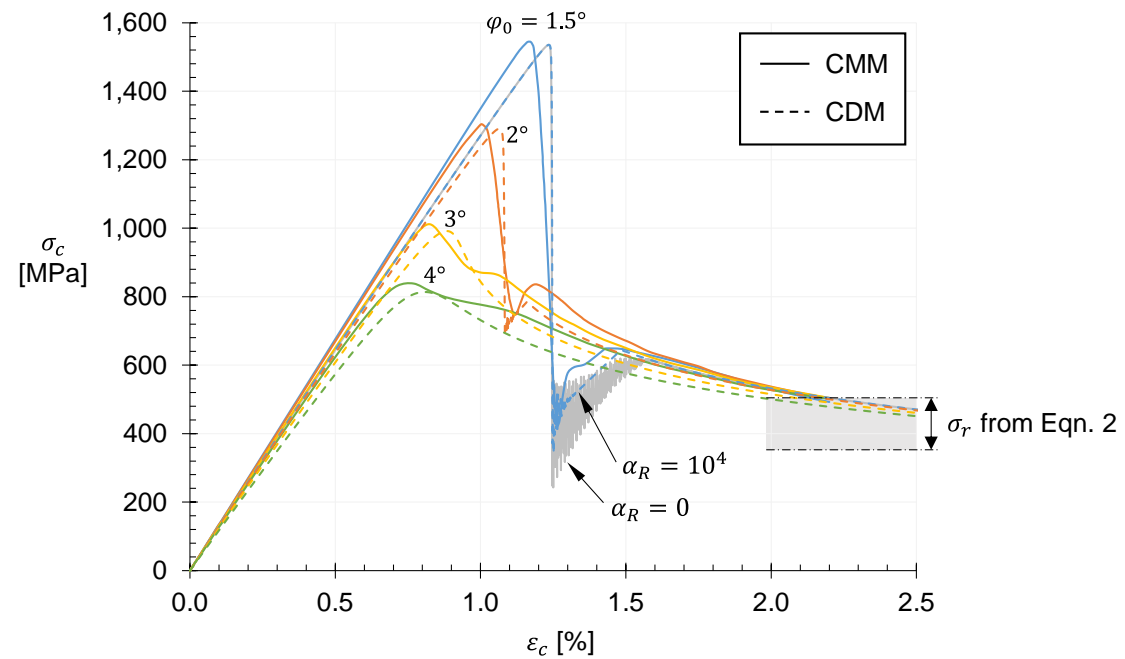

Figure 6. Longitudinal stress-strain response for the mesoscale and micromechanical models.

The effect of fiber nonlinearity (refer back to Eqn. (10)) is shown in Fig. 7 for the CMM and CDM models. The CMM uses $c_{f}=18.4$ obtained from single fiber tensile tests where it is assumed that the nonlinearity is the same in tension and compression. The CDM uses $c_{l}=10$ as obtained by regression using the data from Peterson and Murphy ${ }^{46}$ for a different fiber (IM7/8552). Since this nonlinearity is a function of the fiber only (not the matrix), the two values for the fiber nonlinearity parameter follow approximately the rule of mixtures. The coarse assumptions used in determination of the fiber nonlinearity coefficients for the two models makes it unwise to draw conclusions from the quantitative correlation. Nonetheless, both models have the capability for accounting for fiber nonlinearity and show a pre-peak softening behavior.

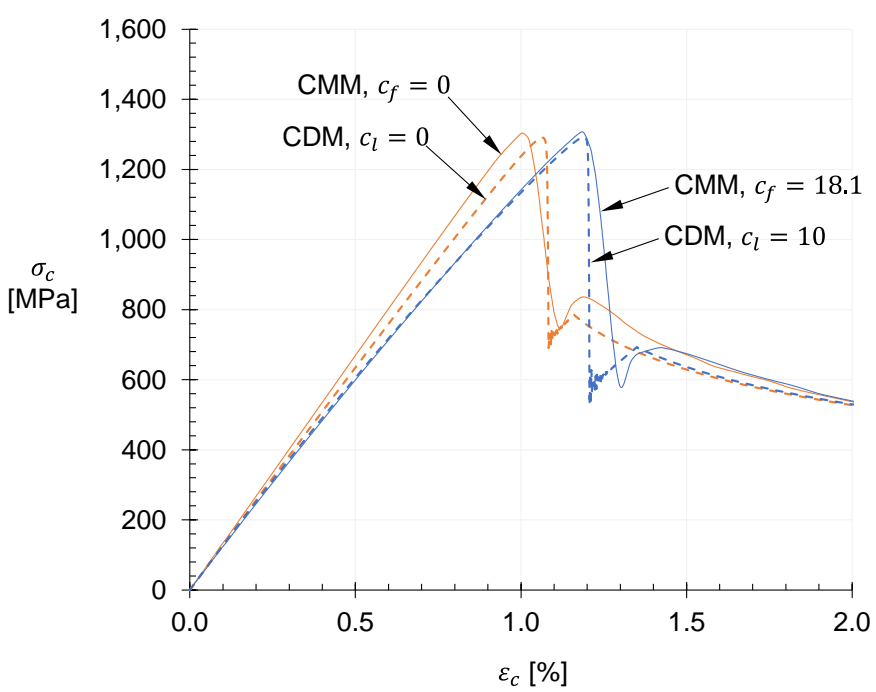

Figure 7. Effect of fiber nonlinearity on the longitudinal stress-strain response for the mesoscale and micromechanical models for $\varphi_{0}=2^{\circ}$.

The strengths from the two models and from Budiansky's fiber kinking theory, Eqn. (1), are shown as a function of $\varphi_{0}$, in Fig. 8. It is observed that the CMM predicts the strength accurately, which is an indication that the model includes the relevant mechanisms of the kinking process. The overall excellent agreement between the models is attributed to the equivalence of the nonlinear shear response.

The misalignment angle $\varphi$ is shown as a function of longitudinal strain in Fig. 9 for $\varphi_{0}=1.5^{\circ}$ and $\varphi_{0}=4^{\circ}$. Since $\varphi=\varphi(z)$ in the CMM, two definitions for $\varphi$ are shown for comparison with the fiber rotation predicted by the CDM model, $\varphi_{\mathrm{CDM}}$. The maximum fiber rotation in the CMM takes place at $z=L / 2$ and is denoted as $\varphi_{\mathrm{CMM}}^{\mathrm{max}}$. The average

American Institute of Aeronautics and Astronautics 
rotation of the kinked fiber is calculated from the transverse deflection at the end of the fiber $u_{y}$, as $\varphi_{\mathrm{CMM}}^{\mathrm{avg}}=$ $\tan ^{-1}\left(u_{y} / L\right)$. The value for $\varphi_{\mathrm{CDM}}$ is calculated using Eqn. (25). In all cases, the fiber misalignment shows slight rotation $\left(\varphi \approx \varphi_{0}\right)$ prior to the strain at which the peak load is attained. When the critical strain corresponding to the peak load is reached, the fiber rotates rapidly into the kinked configuration, which is seen as the abrupt change in $\varphi$ in Fig. 9 at $\varepsilon_{c} \approx 1 \%$. The rotation is much more rapid for small initial imperfections than for large initial imperfections. Under higher strains (in the strain regime that corresponds with the residual stress, $\varepsilon_{c}>1.5 \%$ ) the fibers continue to rotate. The fiber rotation predicted by the CDM is bounded by the average and maximum $\varphi$ from the CMM. It could be argued that $\varphi_{\mathrm{CDM}}$ should match $\varphi_{\mathrm{CMM}}^{\mathrm{max}}$ since both represent the critical or maximum fiber misalignment. The difference between $\varphi_{\mathrm{CDM}}$ and $\varphi_{\mathrm{CMM}}^{\mathrm{max}}$ is most likely due to consideration of fiber bending and periodic boundary conditions in the CMM, both of which affect the fiber rotation and were not included in the CDM. Nonetheless, the agreement between the two models is quite good, further highlighting the efficacy of the relatively low-fidelity mesoscale model at representing the large rotations associated with the fiber kinking process as predicted by the highfidelity micromechanical model.

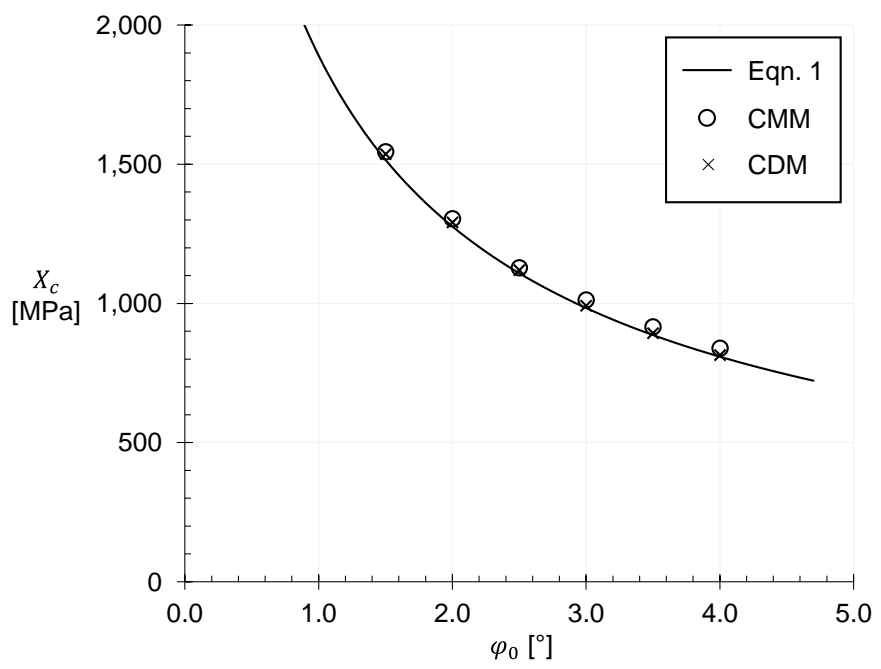

Figure 8. Strength vs. initial misalignment angle.

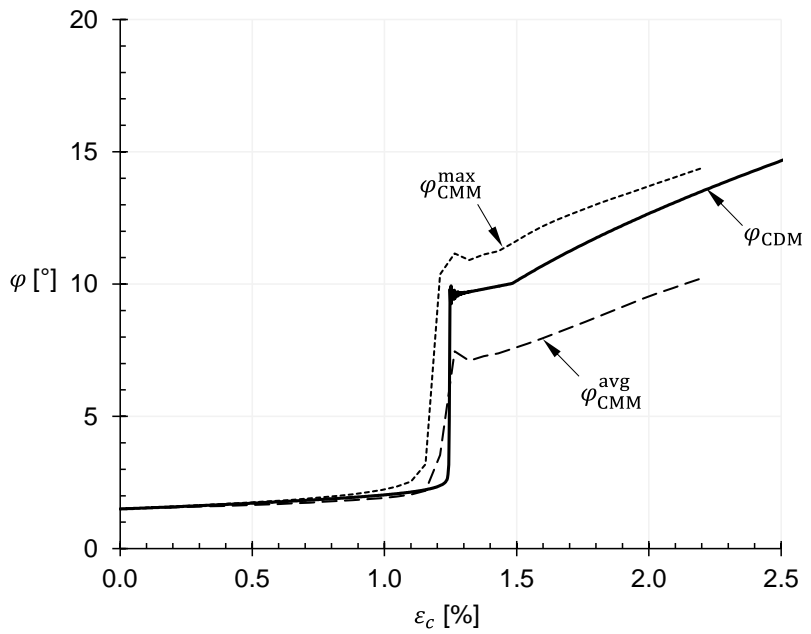

a) $\varphi_{0}=1.5^{\circ}$

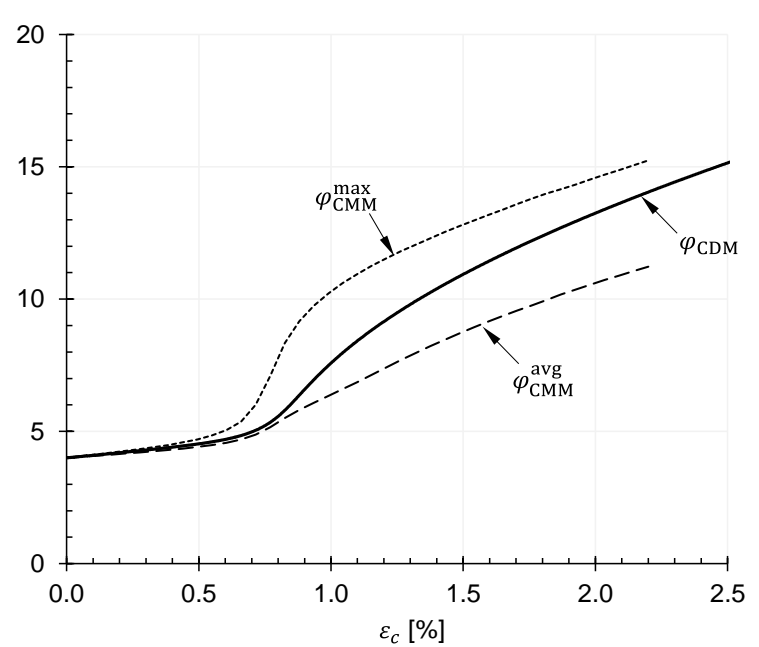

b) $\varphi_{0}=4.0^{\circ}$

Figure 9. Fiber misalignment as a function of longitudinal strain. 


\section{Verification and Validation of the Mesoscale CDM Model}

The mesoscale model was applied to predict the response of unnotched and notched coupon specimens. The unnotched specimen analysis was conducted as a verification study, and the notched coupon analysis was conducted as preliminary validation. In both studies, the IM7/8552 material system was used with the material properties given in Table 6.

Table 6. IM7/8552 material properties inputs for mesoscale model..$^{47}$

\begin{tabular}{|c|c|c|c|c|c|c|c|}
\hline $\begin{array}{c}E_{1} \\
(\mathrm{MPa})\end{array}$ & $\begin{array}{c}E_{2} \\
(\mathrm{MPa})\end{array}$ & $\begin{array}{c}G_{12} \\
(\mathrm{MPa})\end{array}$ & $v_{12}$ & $v_{23}$ & $\begin{array}{c}\alpha \\
\left(\mathrm{MPa}^{1-\eta_{\mathrm{PL}}}\right)\end{array}$ & $\eta$ & $\begin{array}{c}X_{C} \\
(\mathrm{MPa})\end{array}$ \\
\hline 152,689 & 8703 & 5164 & 0.32 & 0.45 & $4.06 \times 10^{-9}$ & 5.4 & 1731 \\
\hline
\end{tabular}

\section{A. Unnotched Compression Specimen}

The unnotched configuration was chosen to resemble the gauge section of test specimens used to measure longitudinal compression strength. The unidirectional specimen has a 5-mm width, 14-mm length, and 6 plies for a thickness of $1.1 \mathrm{~mm}$. Damage was disabled in the regions of the specimen near the ends to force failure in the midsection, as shown in Fig. 10a. The model was meshed with C3D8R elements with enhanced hourglass control enabled. Analyses were conducted with an Abaqus/Explicit step with a duration of 0.1 seconds. Automatic mass scaling was enabled with a target increment size of $10^{-6}$. Three mesh sizes, $0.05 \mathrm{~mm}, 0.1 \mathrm{~mm}$, and $0.2 \mathrm{~mm}$, were used to assess the mesh objectivity of the model prediction. On the top and bottom faces of the specimen at $x=0$ and $x=l$, uniform end shortening was applied and displacements in the $y$ - and $z$-directions are set to zero, as shown in Fig. 10b. End shortening is applied to both ends to reduce the overall dynamic energy in the model.

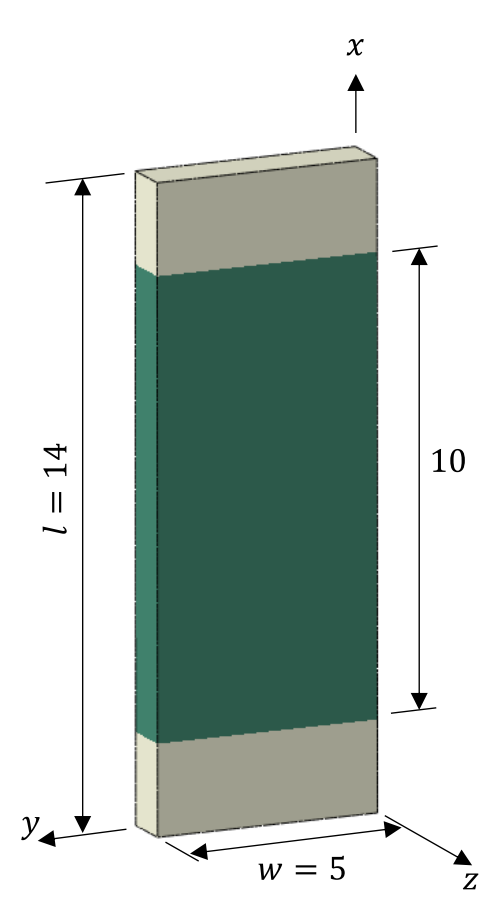

Damage disabled

Damage enabled

a)

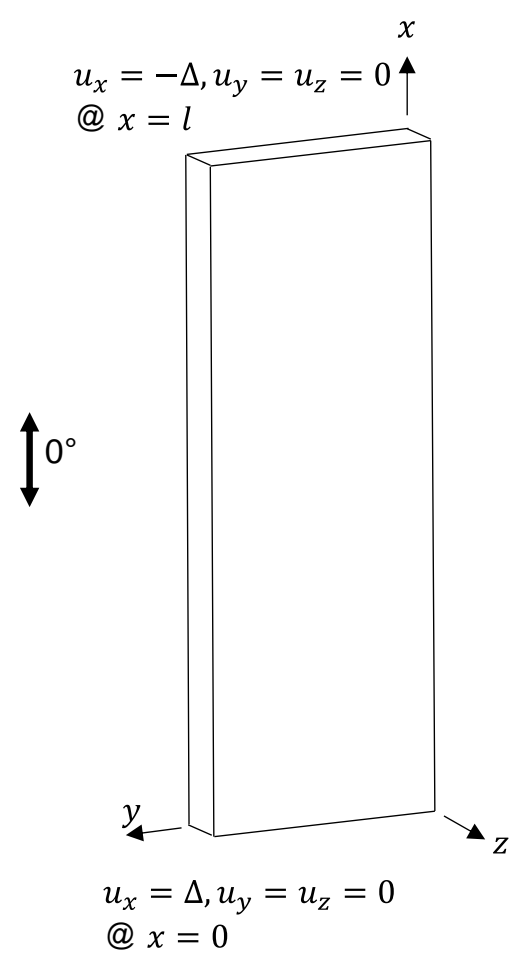

b)
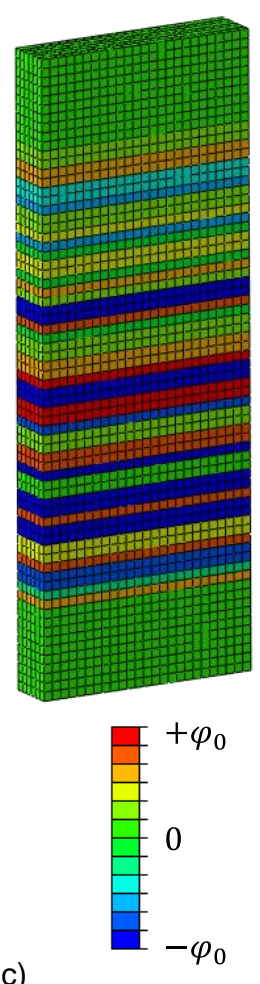

c)

Figure 10. Unnotched compression specimen (a) dimensions (all length dimensions are in $\mathbf{m m}$ ), (b) boundary conditions, and (c) initial fiber misalignment for $l_{e}=0.2 \mathrm{~mm}$.

American Institute of Aeronautics and Astronautics 
A difficulty in the progressive damage analysis of unnotched configurations is the need for a nonuniformity to trigger localization of damage. For fiber kinking, the initial fiber misalignment, $\varphi_{0}$, presents an interesting possibility to achieve a physically based spatial variation that will trigger damage localization in unnotched specimens. Sutcliffe showed the use of random fiber misalignments as an initiation mechanism while studying the role of spatially varying fiber misalignments using a 2-D plane strain finite element model. ${ }^{48,49}$ It should also be recognized that if the fiber misalignment in all elements is the same, an overall shearing occurs when the coupon is compressed due to the anisotropy induced by the misalignment. Such a response is a departure from reality since measured fiber misalignments have a random distribution with a net misalignment near zero. ${ }^{50,51}$ While implementation of a 2-D or 3-D spatial variation of initial fiber misalignments is possible (although complex) using experimental measurements available in the literature ${ }^{38}$, a simple 1-D implementation is used herein. A 1-D variation of fiber misalignments has the advantages of simplicity and consistency with Budiansky's infinite band assumption, which is useful for verification. Thus, a uniform random distribution of fiber misalignments in the interval $\left[-\varphi_{0}, \varphi_{0}\right]$ is applied, where Eqn. (13) and the properties in Table 6 are used to obtain $\varphi_{0}=1.15^{\circ}$. The misalignment angle is assumed to vary only as a function of the longitudinal position, $x$, which is consistent with Budiansky's infinite band assumption. No wavelength is associated with the fiber misalignment. One realization of fiber misalignments used for verification is shown in Fig. 10c for $l_{e}=0.2 \mathrm{~mm}$. All realizations satisfy $\varphi_{\max } / \varphi_{0} \geq 0.97$ where $\varphi_{\max }$ is the absolute maximum misalignment in the model, and so it can be expected that the analysis should reproduce the input strength, $X_{c}$.

The normalized applied stress, $\sigma_{x x} / X_{c}$, versus end shortening, $\Delta$, results are shown in Fig. 11a. It is observed that the model reproduces the strength accurately with all three element sizes. Without element deletion, the analysis crashes at the peak load due to excessive mesh distortion. Using element deletion with the tolerance values provided in Table 7 in Eqns. (29) - (31) enables capturing the load drops shown in Fig. 11. The evolution of plastic strain just before collapse is shown in Fig. 11b and indicates that damage localizes in the band of elements with the largest $\varphi_{0}$ and rapidly propagates across the width of the specimen in a direction corresponding to a kink band angle $\beta=0$, which is consistent with the formulation of the model. The fiber rotation associated with the kink band is evident in the deformed mesh.

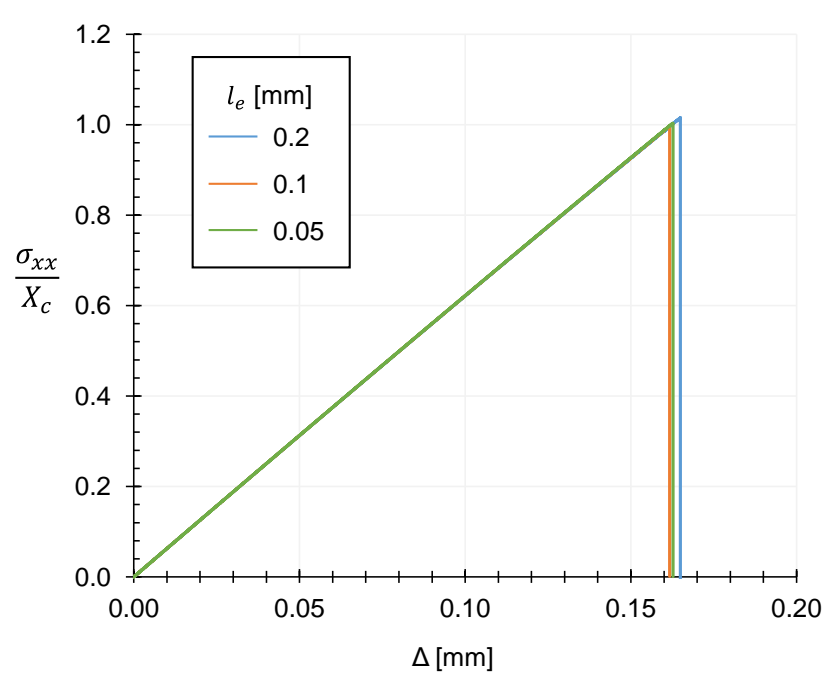

a)

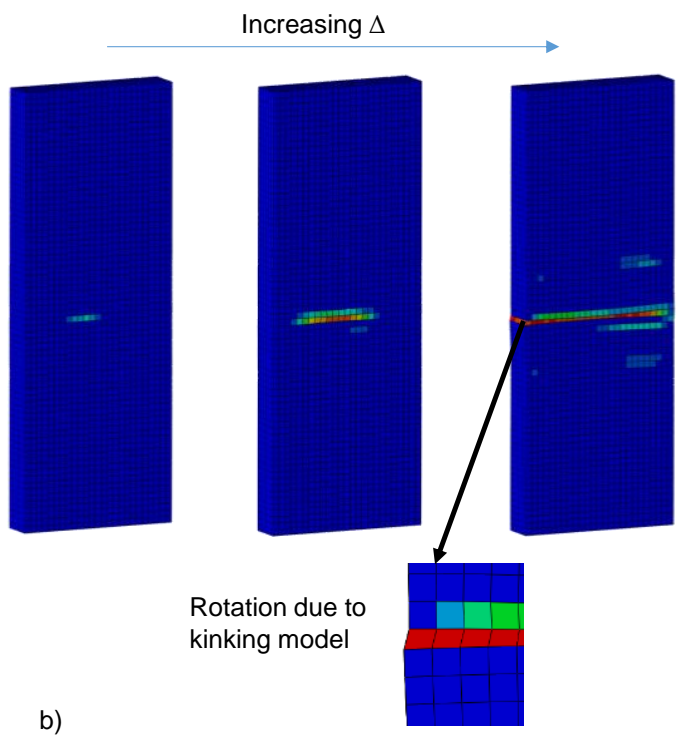

b)

Figure 11. Mesoscale model results for the unnotched compression specimen: (a) structural response and (b) evolution of plastic strain.

Table 7. Element deletion tolerances used in UNC analysis.

\begin{tabular}{|c|c|c|}
\hline$F_{\text {TOL }}$ & $n_{\max }$ & $\gamma_{\text {TOL }}$ \\
\hline 0.25 & $10^{4}$ & $400 \%$ \\
\hline
\end{tabular}

The unique relation between strength and $\varphi_{0}$ given in Eq. (1) may lead to the conclusion that a spatial distribution of $\varphi_{0}$ is no different from spatially distributing strength. However, it should be recognized that fiber misalignment measurements can be used to introduce a length scale associated with the wavelength of misaligned fibers. Although

American Institute of Aeronautics and Astronautics 
not addressed here, a length scale for material variability seems likely to be an important feature for overcoming the limitation of random distributions, where strong elements neighboring weaker elements prevent damage propagation, especially when considering 2-D and 3-D spatial variations. Furthermore, the spatial variation of misalignments has an important constraining effect, where gradients in misalignment arrest rotation of the most severely misaligned fibers, so that the strength is a function of the average misalignment instead of the maximum misalignment ${ }^{28}$. These features should be accounted for in order to predict accurately longitudinal compression failures.

\section{B. Double Edge Notch Compression Specimen}

A double edge notch compression (DENC) specimen configuration inspired by Catalanotti et al. ${ }^{7}$ was used for preliminary validation of the mesoscale CDM model. The specimen configuration and nominal dimensions are shown in Fig. 12. The layup is $\left[(90 / 0)_{8} / 90 /(0 / 90)_{8}\right]$ using unidirectional IM7/8552 prepreg plies. The average cured laminate thickness was $6.141 \mathrm{~mm}$ such that the cured ply thickness was $t_{\mathrm{ply}}=0.186 \mathrm{~mm}$. The specimens were loaded between hardened platens using displacement control applied quasi-statically at a rate of $0.1 \mathrm{~mm} / \mathrm{min}$. The loading platens were adjusted so that strain was evenly distributed front-to-back and left-to-right across the specimen. Two digital image correlation (DIC) systems were used to monitor strains on the front $\left(z=t_{L}\right)$ and back surfaces $(z=0)$ in real time during the tests. A third DIC system was used to monitor the loading platens to characterize rigid body rotation, though the measured platen rotations were found to be negligible.

A reduced thickness DENC specimen modeled with three plies was developed as shown in Fig. 13. The ply thicknesses are scaled proportionally so that the modeled laminate thickness is $t_{M}=0.1 t_{L}$ and the ratio of the thicknesses of the $0^{\circ}$ and $90^{\circ}$ plies $\left(t_{0} / t_{90}\right)$ is the same in the test specimen and the model. Each ply was modeled with one layer of C3D8R elements with enhanced hourglass control.

In a similar fashion as in the unnotched compression specimen model, damage is enabled only in the region near the notches where damage is expected to occur. The material properties given in Table 6 were used. Fiber nonlinearity was considered with $c_{l}=10$. Cohesive elements (COH3D8) were used at the two ply interfaces in the region where damage is enabled to allow for delamination during the analysis. The properties used for the cohesive elements are listed in Table 8. The model did not include progressive intralaminar matrix damage in the $0^{\circ}$ plies. A simple study with splitting cracks inserted into the model a priori was done to help understand the role of splitting and is described in the following paragraphs. Damage in the $90^{\circ}$ plies was ignored in the simulations based on the assumption that the $0^{\circ}$ plies dominate the response. Additional work is required to investigate the effects of accounting for matrix damage progression.
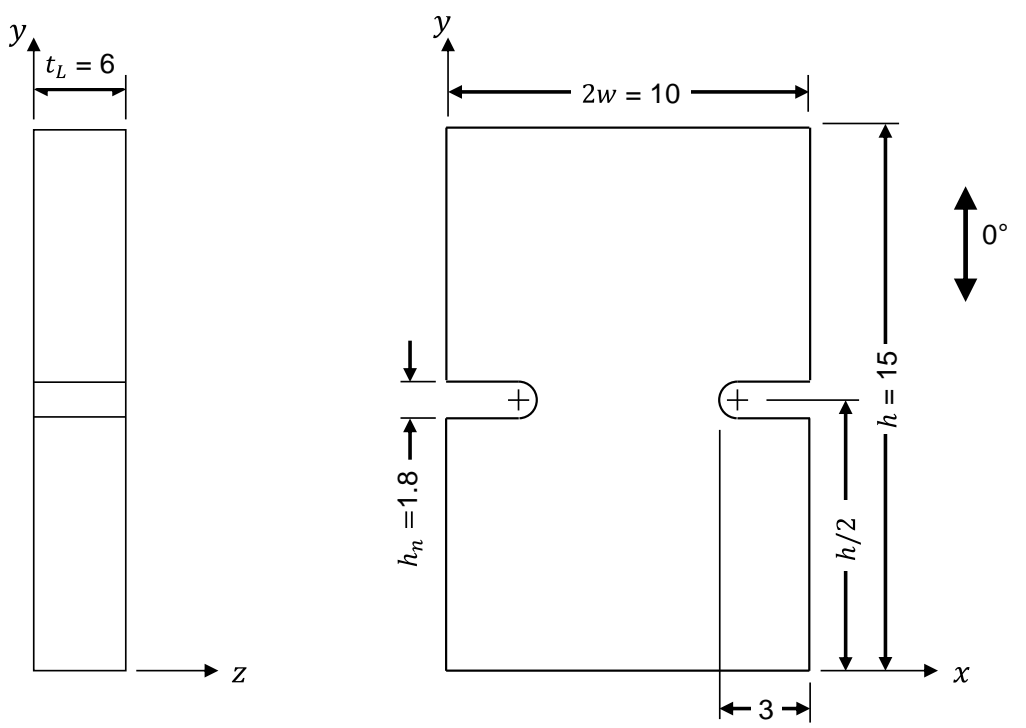

Figure 12. DENC specimen configuration with nominal dimensions in $\mathbf{m m}$.

American Institute of Aeronautics and Astronautics 


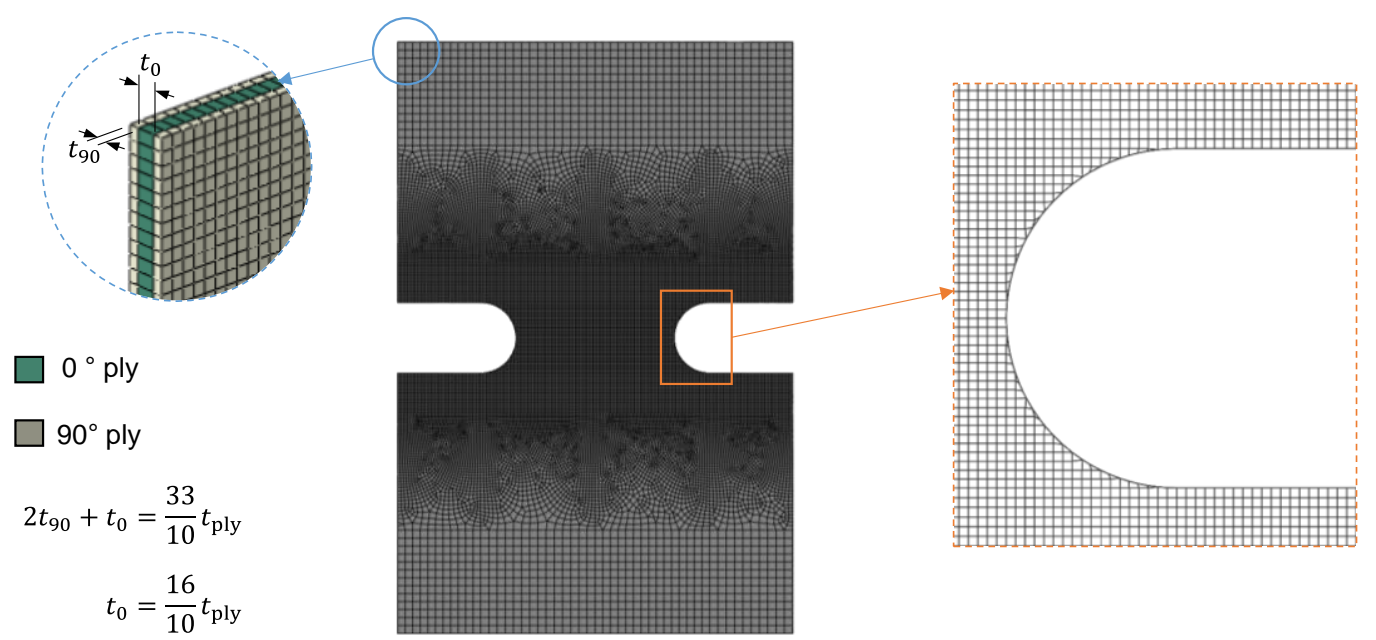

Figure 13. DENC specimen mesh.

Table 8. Properties for matrix damage. ${ }^{47}$

\begin{tabular}{|c|c|c|c|c|}
\hline $\begin{array}{c}N \\
(\mathrm{MPa})\end{array}$ & $\begin{array}{c}S \\
(\mathrm{MPa})\end{array}$ & $\begin{array}{c}G_{N}^{c} \\
\left(\mathrm{~kJ} / \mathrm{m}^{2}\right)\end{array}$ & $\begin{array}{c}G_{S}^{c} \\
\left(\mathrm{~kJ} / \mathrm{m}^{2}\right)\end{array}$ & $\eta_{\mathrm{BK}}$ \\
\hline 80.1 & 97.6 & 0.24 & 0.739 & 2.07 \\
\hline
\end{tabular}

An aligned mesh was used with a typical element size $l_{e}$ of $0.05 \mathrm{~mm}$ in the region where damage was enabled. This mesh size was chosen for mesh convergence of the axial stress field near the notch tip. Since this mesh size is on the order of the kink band width $w_{\mathrm{kb}}$ reported in the literature for IM7/8552, and the model requires $l_{e} \geq w_{\mathrm{kb}}$, it was assumed that $w_{\mathrm{kb}}=l_{e}=0.05 \mathrm{~mm}$. Uniform end shortening was applied to the face where $y=h$ and the opposite face was constrained in the $y$-direction. The surface $z=0$ was constrained in the $z$-direction to prevent buckling, which was required since the model had a reduced thickness. The node located at the origin was pinned to prevent rigid body translation. The analysis was performed using Abaqus/Explicit with a step with a duration of 0.1 seconds. Automatic mass scaling was enabled with a target increment size of $10^{-6}$.

Three cases of spatially varying initial misalignments were considered in the $0^{\circ}$ ply of the DENC model. The initial misalignments considered herein are shown in Fig. 14 where only the region inside in the dashed rectangle in the schematic is shown for each case in parts (a) - (c) of the figure. The first case, denoted 'A', simply alternates between $+\varphi_{0}$ and $-\varphi_{0}$ for each row of elements, as shown in Fig. 14a. The second initial misalignment case is a random uniform distribution denoted 'RU' as shown in Fig. 14b. The third case of initial misalignment was a modified random distribution, denoted 'RM' and considers the situation where the misalignments near the notch tip are small. The 'RM' realization is shown in Fig. $14 \mathrm{c}$ and was created by adding the condition $\left|\varphi_{i}\right| \leq \varphi_{0} / 2:\left(h-h_{n}\right) / 2 \leq y_{i} \leq(h+$ $\left.h_{n}\right) / 2$ where $\varphi_{i}$ is the misalignment at the material point with position, $y_{i}$. The alternating approach ' $\mathrm{A}$ ' produces a severe worst-case condition where large misalignments are located throughout the region of stress concentration. The other two cases 'RU' and 'RM' use a random distribution in a manner similar to that used for the UNC model where $\varphi_{0}$ is varied in the loading direction. For the random initial misalignments, it is expected that the proximity of large misalignments to the stress concentration near the notch tip will have a significant effect on the predicted strength. Thus, cases of large and small misalignments in the proximity of the notch tip are considered.

American Institute of Aeronautics and Astronautics 


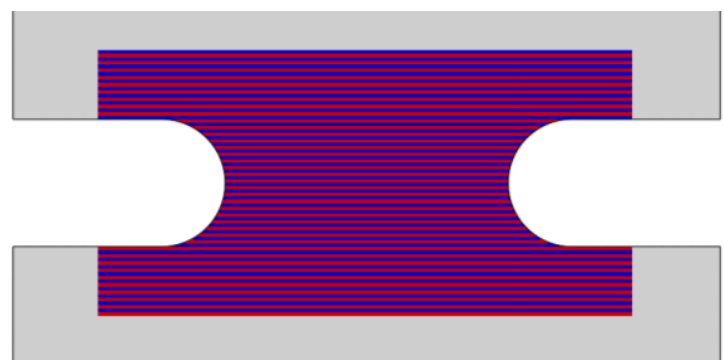

a) 'A'

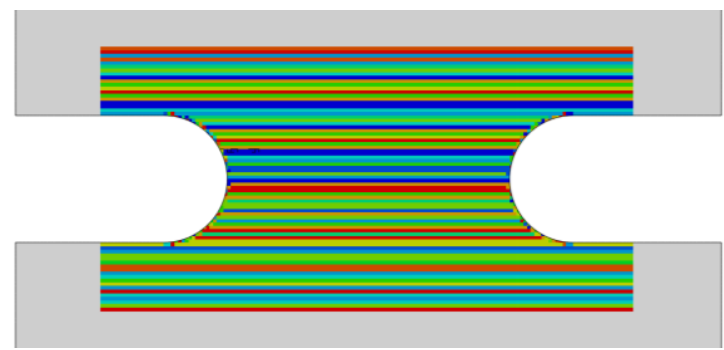

b) 'RU'

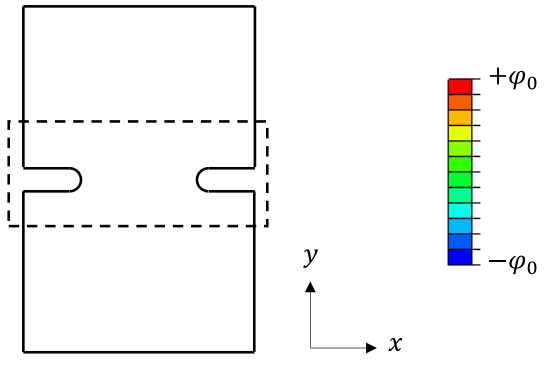

d) Schematic

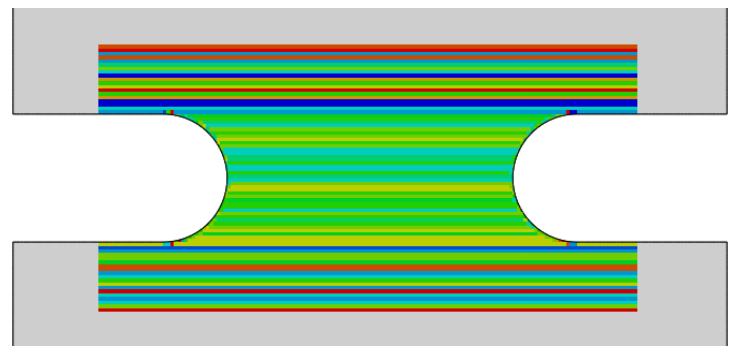

c) 'RM'

Figure 14. Initial fiber misalignments considered in the DENC analyses: (a) alternating distribution, (b) uniform random distribution, and (c) modified random distribution where the region of interest is shown in the schematic in (d). Damage is disabled in the grey regions.

The characteristic load versus displacement response from the test data and several analyses are shown in Fig. 15. The compressive displacement, $\Delta_{c}$, is measured using the DIC systems between two far field points with an initial separation of $11.25 \mathrm{~mm}$ along the centerline of the specimen, $x=w$, as shown in the schematic in the figure. The DIC data from the front surface (blue) and back surface (red) are shown as dashed lines. The test data deviates from the initial linear response (shown with a solid black line) at about $5 \mathrm{kN}$. Visual observations of fiber kinking accompanied by audible events initiated at $14.9 \mathrm{kN}$, and continued until the specimen collapsed. The specimen sustained a peak load of $15.6 \mathrm{kN}$, then subsequently failed. The analysis results for the three distributions of initial fiber misalignment angle are also shown in Fig. 15 as solid lines. The analysis results shown in Fig. 15 were obtained with the matrix damage capability disabled. There was more nonlinearity observed in the test data than in the analysis predictions, which could be due to underestimation of $c_{l}$ or other material nonlinearities not included in the model. The effect on the peak load of the initial fiber misalignment distribution is significant, with a $44 \%$ difference in predicted peak load between the three cases. While the three cases bound the potential effects of fiber waviness in the 1-direction, all of the analyses under predict the peak load measured in the test. The strength predicted in the 'RM' case is in relatively good agreement with the test $(9.3 \%$ error). The correlation in load at which kinking occurs is also in good agreement ( $5 \%$ error). However, the 'RM' case represents an assumption of initial fiber misalignment that appears idealistic. As such, apparently other mechanisms not included in this model are required to obtain an accurate prediction.

American Institute of Aeronautics and Astronautics 


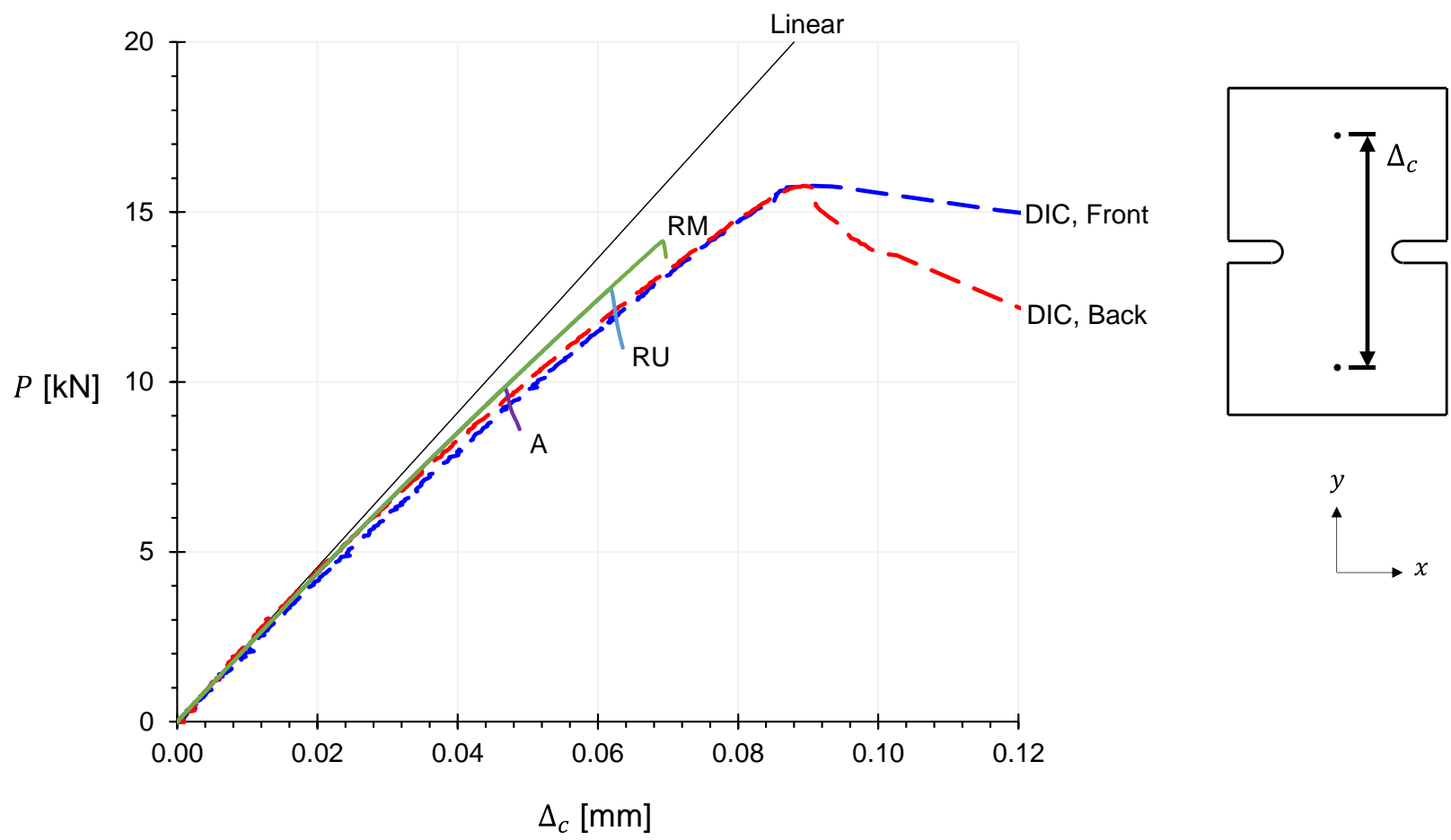

Figure 15. DENC structural response from test and analysis.

The sequence of the failure process predicted in the $0^{\circ}$ ply is shown in Fig. 16 for the alternating misalignment ' $A$ ' case where the contour plot shows the longitudinal stress in the $0^{\circ} \mathrm{ply}$. The stress at the notch tip exceeds the strength since the neighboring $90^{\circ}$ plies and stress gradient at the notch tip introduce a constraining effect ${ }^{52,53}$ and therefore limit the shear strain which delays damage initiation. This effect on damage initiation is a desirable behavior since it is well documented that the local constraints on the material have a large effect on measurements of compressive strength and therefore should play a role in model predictions ${ }^{29,48,49,52,53}$. Fiber kinking initiates at one notch tip, as shown by the arrow in frame ' 3 ' in Fig. 16, probably due to small numerical differences between the stress states at the two notch tips in the otherwise nominally symmetric specimen. The kink bands are label as ' $\mathrm{kb}$ ' in frames ' 4 ' and ' 5 ' in Fig. 16 with white brackets showing the length. The location of fiber kinking is offset from the centerline of the notch $(y=h / 2)$, as shown by the black arrow in frame ' 4 ' in Fig. 16, which is consistent with observations in similar specimens. ${ }^{37}$ Delamination propagated along with the kink. As the specimen fails, the outer $90^{\circ}$ ply begins to buckle.

The test revealed that there was an additional load capacity of $0.7 \mathrm{kN}$ beyond the load level where fiber kinking is identified $(14.9 \mathrm{kN})$. In contrast, the model predicts collapse very shortly after the kink band initiates as shown by the small increase in the load level from frame ' 3 ' where kinking is first observed to the peak load, where the kink band propagates rapidly across the specimen. Apparently, the model prediction for kinking propagation is too brittle.

Matrix splitting has been identified as an important damage mechanism in longitudinal compressive failure ${ }^{20}$. Additionally, matrix splitting is important when considering failure at notches since splitting damage may blunt the notch tip stress concentration and thus increase the peak load. No detailed observations of pre-peak matrix damage were available from the DENC test, and no verification or validation has been completed for modeling the interaction of matrix damage and fiber kinking using the present model. However, a simple study was conducted to investigate the relative significance of matrix splits on the overall structural response as follows. Matrix splitting cracks of different lengths were pre-seeded at the notch tip by setting the associated damage variable to one in the initial conditions for the cracked elements. Delaminations at the ply interfaces above and below the splits were also preseeded by deleting the adjacent cohesive elements. The analyses were run using the random uniform fiber misalignment ('RU') model. Three split lengths were considered: $0.5 \mathrm{~mm}, 1.0 \mathrm{~mm}$, and $1.5 \mathrm{~mm}$. The structural response is shown in Fig. 17 for the three split lengths, the model with no split, and the test. It was observed that a relatively small splits of $0.5 \mathrm{~mm}$ reduces the peak load, which was not expected. While matrix splits blunt the notch tip stress concentration, splits also reduce the constraint on shear strain of the neighboring elements, increasing the propensity for kinking. Longer splits significantly increased the strength predicted by the model since the blunting of

American Institute of Aeronautics and Astronautics 
the stress concentration becomes more significant than the reduction in local constraint. While the results suggest good correlation in strength for a split of about $1.5 \mathrm{~mm}$, it should be noticed that the split does not account for the pre-peak nonlinearity observed in the test, suggesting that other significant mechanisms are not accounted for in the model. Although this study on splitting is simplistic, it demonstrates that accurate longitudinal failure prediction relies on accurate prediction of matrix crack kinematics, the resulting stress redistribution, and the interaction of matrix and fiber damage modes.
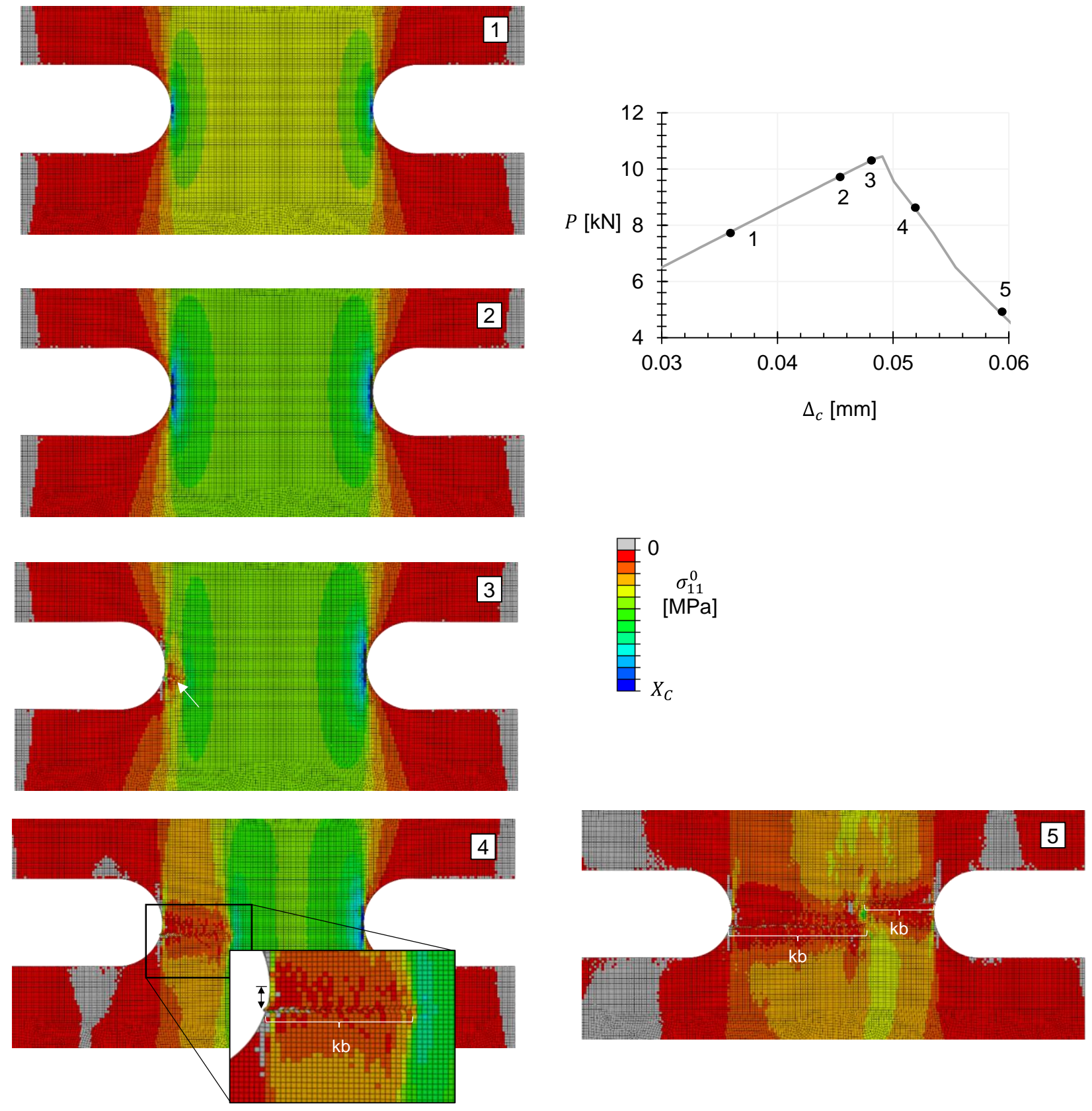

Figure 16. Predicted failure process in the $0^{\circ}$ ply for case ' $A$ ' in Fig. 14. 


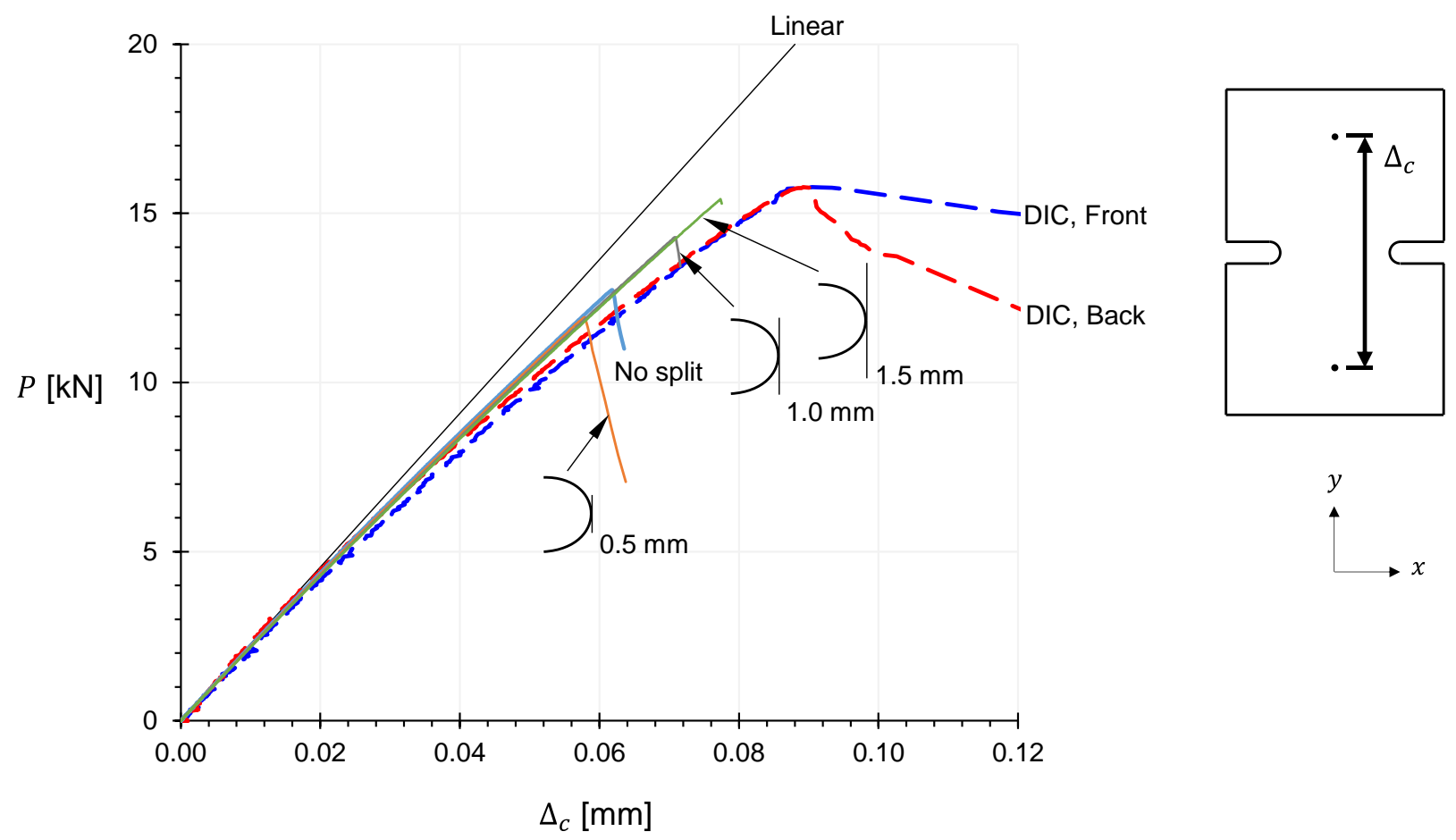

Figure 17. Effect of splitting cracks at the notch tip on the DENC structural response.

\section{Concluding Remarks}

Recent developments towards a mesoscale constitutive model for fiber kinking were summarized in this paper. A mesoscale model is formulated with consideration for the kinematics of fiber kinking including shear instability and a post-peak non-zero residual stress. A high-fidelity 3-D micromechanical finite element model was used to assess the assumptions of the mesoscale model. The comparison between the results of the mesoscale and micromechanical models shows a remarkable correlation in strength, post-peak residual stress, and fiber rotation. The quality of the correlation indicates that the significant features of the kinking process are included in the relatively simple mesoscale model.

The mesoscale model was verified through analysis of an unnotched coupon specimen. The initial misalignment angle was randomly varied in order to trigger localization in the model. Preliminary results for the unnotched specimen show that the model is capable of predicting initiation and propagation of a kink band. Analyses with three mesh sizes suggest that the model results are objective with respect to the mesh size.

Preliminary validation of the mesoscale model was accomplished using a DENC specimen. Qualitatively, the model demonstrates several key features including: accurate prediction of kinking initiation location, effect of confinement at the notch tip, and shear deformation in the kink band. Quantitatively, the model shows that consideration for random fiber misalignments, accurate prediction of matrix splitting cracks, and delamination are needed to obtain good agreement with the test results. Future work is required to verify and validate kinking propagation and the limitations of ignoring fiber bending. The present model could be extended by considering 2-D or 3-D variations of initial fiber misalignments based on experimental measurements, out-of-plane kinking, the interaction fiber kinking and splitting, and structural size effects.

\section{Acknowledgements}

The authors wish to acknowledge the contributions of Mr. Wade Jackson, Mr. Michael O'Neil, Dr. Nathaniel Gardner, and Dr. David Dawicke in performing the DENC tests. The authors are also grateful for the comments and suggestions from Dr. Frank Leone and Dr. Carlos Dávila.

American Institute of Aeronautics and Astronautics 


\section{References}

${ }^{1}$ Engelstad, S. P., and Clay, S. B., "Comparison of Composite Damage Growth Tools for Static Behavior of Notched Composite Laminates," Journal of Composite Materials, Vol. 51, No. 10, 2017, pp. 1493-1524.

2 Matzenmiller, A., Lubliner, J., and Taylor, R. L., "A Constitutive Model for Anisotropic Damage in FiberComposites," Mechanics of Materials, Vol. 20, No. 2, 1995, pp. 125-152.

${ }^{3}$ Maimí, P., Camanho, P. P., Mayugo, J.-A., and Dávila, C. G., "A Thermodynamically Consistent Damage Model for Advanced Composites," NASA/TM-2006-214282, 2006.

${ }^{4}$ Pinho, S. T., Robinson, P., and Iannucci, L., "Fracture Toughness of the Tensile and Compressive Fibre Failure Modes in Laminated Composites," Composites Science and Technology, Vol. 66, No. 13, 2006, pp. 2069-2079.

${ }^{5}$ Catalanotti, G., Camanho, P. P., Xavier, J., Dávila, C. G., and Marques, A. T., "Measurement of Resistance Curves in the Longitudinal Failure of Composites Using Digital Image Correlation," Composites Science and Technology, Vol. 70, No. 13, 2010, pp. 1986-1993.

${ }^{6}$ Laffan, M. J., Pinho, S. T., Robinson, P., Iannucci, L., and McMillan, A. J., "Measurement of the Fracture Toughness Associated with the Longitudinal Fibre Compressive Failure Mode of Laminated Composites," Composites Part A: Applied Science and Manufacturing, Vol. 43, No. 11, 2012, pp. 1930-1938.

${ }^{7}$ Catalanotti, G., Xavier, J., and Camanho, P. P., "Measurement of the Compressive Crack Resistance Curve of Composites Using the Size Effect Law," Composites Part A: Applied Science and Manufacturing, Vol. 56, 2014, pp. 300-307.

8 Wind, J. L., Waas, A. M., and Jensen, H. M., "Initiation of Failure at Notches in Unidirectional Fiber Composites," Composite Structures, vol. 122, 2015, pp. 51-56.

${ }^{9}$ Iarve, E. V., Hoos, K., Braginsky, M., Zhou, E., and Mollenhauer, D. H., "Tensile and Compressive Strength Prediction in Laminated Composites by Using Discrete Damage Modeling," 56 th AIAA/ASME/ASCE/AHS/ASC Structures, Structural Dynamics, and Materials Conference, Kissimmee, FL, Jan. 2015.

${ }^{10}$ Joseph, A., Paul, D., and Waas, A., "Intra-inter Crack Band Model (I2CBM) for Progressive Damage and Failure Analysis of Bolted Joints," 58 th AIAA/ASME/ASCE/AHS/ASC Structures, Structural Dynamics, and Materials Conference, Grapevine, TX, Jan. 2017.

${ }^{11}$ Budiansky, B., "Micromechanics," Computers \& Structures, Vol. 16, No. 1, 1983, pp. 3-12.

${ }^{12}$ Budiansky, B., and Fleck, N. A., "Compressive Failure of Fibre Composites," Journal of the Mechanics and Physics of Solids, Vol. 41, No. 1, 1993, pp. 183-211.

${ }^{13}$ Budiansky, B., Fleck, N. A., and Amazigo, J. C., "On Kink-Band Propagation in Fiber Composites," Journal of the Mechanics and Physics of Solids, Vol. 46, No. 9, 1998, pp. 1637-1653.

${ }^{14}$ Ramberg, W., and Osgood, W. R., "Description of Stress-Strain Curves by Three Parameters," National Advisory Committee For Aeronautics Technical Note 902, 1943.

${ }^{15}$ Bergan, A. C., and Leone Jr., F. A., "A Continuum Damage Mechanics Model to Predict Kink-Band Propagation Using Deformation Gradient Tensor Decomposition," American Society for Composites $31^{\text {st }}$ Technical Conference Williamsburg, VA, Sept. 2016.

${ }^{16}$ Costa, S., Gutkin, R., and Olsson, R., "Finite Element Implementation of a Model for Longitudinal Compressive Damage Growth with Friction," $17^{\text {th }}$ European Conference on Composite Materials, Munich, Germany, Jun. 2016.

${ }^{17}$ Costa, S., Gutkin, R., and Olsson, R., "Mesh Objective Implementation of a Fibre Kinking Model for Damage Growth with Friction," Composite Structures, Vol. 168, 2017, pp. 384-391.

${ }^{18}$ Gutkin, R., Costa, S., and Olsson, R., "A Physically Based Model for Kink-Band Growth and Longitudinal Crushing of Composites Under 3D Stress States Accounting for Friction," Composites Science and Technology, Vol. 135, 2016, pp. 39-45.

${ }^{19}$ Yerramalli, C., and Waas, A. M., "The Effect of Fiber Diamater on the Compressive Strength of Composites - A 3D Finite Element Based Study," Computer Modeling in Engineering Sciences, Vol. 6, No. 1, 2004, pp. 1-16.

${ }^{20}$ Prabhakar, P., and Waas, A. M., "Interaction Between Kinking and Splitting in the Compressive Failure of Unidirectional Fiber Reinforced Laminated Composites," Composite Structures, Vol. 98, 2013, pp. 85-92.

${ }^{21}$ Davidson, P., and Waas, A. M., "Mechanics of Kinking in Fiber-Reinforced Composites Under Compressive Loading," Mathematics and Mechanics of Solids, Vol. 21, No. 6, 2014, pp. 667-684.

${ }^{22}$ Bai, X., Bessa, M. A., Melro, A. R., Camanho, P. P., Guo, L., and Liu, W. K., "High-Fidelity Micro-Scale Modeling of the Thermo-Visco-Plastic Behavior of Carbon Fiber Polymer Matrix Composites," Composite Structures, Vol. 134, 2015, pp. 132-141.

${ }^{23}$ Naya, F., Herráez, M., Lopes, C. S., González, C., Van der Veen, S., and Pons, F., "Computational Micromechanics of Fiber Kinking in Unidirectional FRP Under Different Environmental Conditions," Composites Science and Technology, Vol. 144, 2017, pp. 26-35.

American Institute of Aeronautics and Astronautics 
${ }^{24}$ Leone Jr., F. A., Bergan, A. C., and Dávila, C. G., “CompDam - Deformation Gradient Decomposition (DGD)," https://github.com/nasa/CompDam_DGD, commit: 346cc80, 2017.

${ }^{25}$ Leone Jr., F. A., "Deformation Gradient Tensor Decomposition for Representing Matrix Cracks in Fiber-Reinforced Materials," Composites Part A: Applied Science and Manufacturing, Vol. 76, Sep. 2015, pp. 334-341.

${ }^{26}$ Le Goff, E., Bois, C., and Wargnier, H., "A Progressive Intra- and Inter-Laminar Damage Model to Predict the Effect of Out-of-Plane Confinement on Pin-Bearing Behaviour of Laminated Composites," Journal of Composite Materials, Vol. 51, No. 4, 2017, pp. 433-450.

${ }^{27}$ ABAQUS Online Documentation: Version 2017, Providence, RI: Dassault Systèmes Simulia Corporation, 2017.

${ }^{28}$ Wisnom, M. R., "Finite Element Modeling of Shear Instability under Compression in Unidirectional Carbon-Fiber Composites," Journal of Thermoplastic Composite Materials, Vol. 7, No. 4, 1994, pp. 352-363.

${ }^{29}$ Smoot, M. A., "Compressive response of Hercules AS1/3501-6 graphite/epoxy composites," Center for Composite Materials, Newark, Delaware, 1982.

${ }^{30}$ Bažant, Z. P., and Oh, B. H., "Crack Band Theory for Fracture of Concrete," Matériaux et Construction, Vol. 16, No. 3, 1983, pp. 155-177.

${ }^{31}$ Svensson, D., Alfredsson, K. S., Stigh, U., and Jansson, N. E., "Measurement of Cohesive Law for Kink-Band Formation in Unidirectional Composite," Engineering Fracture Mechanics, Vol. 151, 2016, pp. 1-10.

${ }^{32}$ Zobeiry, N., Vaziri, R., and Poursartip, A., "Characterization of Strain-Softening Behavior and Failure Mechanisms of Composites Under Tension and Compression," Composites Part A: Applied Science and Manufacturing, Vol. 68, 2015, pp. 29-41.

${ }^{33}$ Hapke, J., Gehrig, F., Huber, N., Schulte, K., and Lilleodden, E. T., “Compressive Failure of UD-CFRP Containing Void Defects: In Situ SEM Microanalysis," Composites Science and Technology, Vol. 71, No. 9, Jun. 2011, pp. $1242-1249$.

${ }^{34}$ Jumahat, A., Soutis, C., Jones, F. R., and Hodzic, A., "Fracture Mechanisms and Failure Analysis of Carbon Fibre/Toughened Epoxy Composites Subjected to Compressive Loading," Composite Structures, Vol. 92, No. 2, 2010, pp. 295-305.

${ }^{35}$ Gutkin, R., Pinho, S. T., Robinson, P., and Curtis, P. T., "On the Transition from Shear-Driven Fibre Compressive Failure to Fibre Kinking in Notched CFRP Laminates under Longitudinal Compression," Composites Science and Technology, Vol. 70, No. 8, 2010, pp. 1223-1231.

${ }^{36}$ Soutis, C., "Failure of Notched CFRP Laminates due to Fibre Microbuckling: a Topical Review," Journal of the Mechanical Behavior of Materials, Vol. 6, No. 4, 1996, pp. 309-330.

${ }^{37}$ Bergan, A. C., and Garcea, S. C., "In-Situ Observations of Longitudinal Compression Damage in Carbon- Epoxy Cross Ply Laminates Using Fast Synchrotron Radiation Computed Tomography," American Society for Composites $32^{\text {nd }}$ Technical Conference, West Lafayette, IN, Oct. 2017.

${ }^{38}$ Gutkin, R., Pinho, S. T., Robinson, P., and Curtis, P. T., "Micro-Mechanical Modelling of Shear-Driven Fibre Compressive Failure and of Fibre Kinking for Failure Envelope Generation in CFRP Laminates," Composites Science and Technology, Vol. 70, No. 8, 2010, pp. 1214-1222.

${ }^{39}$ Benzeggagh, M. L., and Kenane, M., "Measurement of Mixed-Mode Delamination Fracture Toughness of Unidirectional Glass/Epoxy Composites with Mixed-Mode Bending Apparatus," Composites Science and Technology, Vol. 56, No. 4, 1996, pp. 439-449.

${ }^{40}$ Herráez, M., Mora, D., Naya, F., Lopes, C. S., González, C., and LLorca, J., "Transverse Cracking of Cross-Ply Laminates: A Computational Micromechanics Perspective," Composites Science and Technology, Vol. 110, 2015, pp. 196-204.

${ }^{41}$ Canal, L. P., González, C., Segurado, J., and LLorca, J., "Intraply Fracture of Fiber-Reinforced Composites: Microscopic Mechanisms and Modeling," Composites Science and Technology, Vol. 72, No. 11, 2012, pp. 12231232.

${ }^{42}$ Naya, F., González, C., Lopes, C. S., Van der Veen, S., and Pons, F., "Computational Micromechanics of the Transverse and Shear Behavior of Unidirectional Fiber Reinforced Polymers Including Environmental Effects," Composites Part A: Applied Science and Manufacturing, Vol. 92, 2017, pp. 146-157.

43، "ASTM Standard D3518. 'Standard Test Method for In-Plane Shear Response of Polymer Matrix Composite Materials by Tensile Test of a $\pm 45^{\circ}$ Laminate,"” Annual Book of ASTM Standards, W. ASTM Int., 2013.

${ }^{44}$ Marlett, K., Ng, Y., and Tomblin, J., "Hexcel 8552 AS4 Unidirectional Prepreg at 190 gsm \& 35\% RC Qualification Material Property Data Report," NIAR CAM-RP-2010-002 Rev A, 2011.

${ }^{45}$ Pinho, S. T., Dávila, C. G., Camanho, P. P., Iannucci, L., and Robinson, P., "Failure models and criteria for FRP under in-plane or three-dimensional stress states including shear non-linearity," NASA/TM-2005-213530, 2005.

${ }^{46}$ Peterson, M. E., and Murphey, T. W., "High Strain Flexural Characterization of Thin CFRP Unidirectional Composite Lamina," American Society for Composites 31 ${ }^{\text {st }}$ Technical Conference, Williamsburg, VA, Sept. 2016.

American Institute of Aeronautics and Astronautics 
${ }^{47}$ Wanthal, S., Schaefer, J. D., Justusson, B., Hyder, I., Engelstad, S., and Rose, C., "Verification and Validation Process for Progressive Damage and Failure Analysis Methods in the NASA Advanced Composites Consortium," American Society for Composites $32^{\text {nd }}$ Technical Conference, West Lafayette, IN, Oct. 2017.

${ }^{48}$ Lemanski, S. L., and Sutcliffe, M. P. F., "Compressive Failure of Finite Size Unidirectional Composite Laminates with a Region of Fibre Waviness," Composites Part A: Applied Science and Manufacturing, Vol. 43, No. 3, 2012, pp. 435-444.

${ }^{49}$ Sutcliffe, M. P. F., "Modelling the Effect of Size on Compressive Strength of Fibre Composites with Random Waviness," Composites Science and Technology, Vol. 88, Nov. 2013, pp. 142-150.

${ }^{50}$ Czabaj, M. W., Riccio, M. L., and Whitacre, W. W., "Numerical Reconstruction of Graphite/Epoxy Composite Microstructure Based on Sub-Micron Resolution X-ray Computed Tomography," Composites Science and Technology, Vol. 105, 2014, pp. 174-182.

${ }^{51}$ Fast, T., Scott, A. E., Bale, H. A., and Cox, B. N., "Topological and Euclidean Metrics Reveal Spatially Nonuniform Structure in the Entanglement of Stochastic Fiber Bundles," Journal of Materials Science, Vol. 50, No. 6, 2015, pp. 2370-2398.

${ }^{52}$ Wisnom, M. R., "Analysis of Shear Instability in Compression Due to Fibre Waviness," Journal of Reinforced Plastics and Composites, Vol. 12, No. 11, 1993, pp. 1171-1189.

${ }^{53}$ Wisnom, M. R., "The Effect of Fibre Waviness on the Relationship between Compressive and Flexural Strengths of Unidirectional Composites," Journal of Composite Materials, Vol. 28, No. 1, 1994, pp. 66-76.

American Institute of Aeronautics and Astronautics 